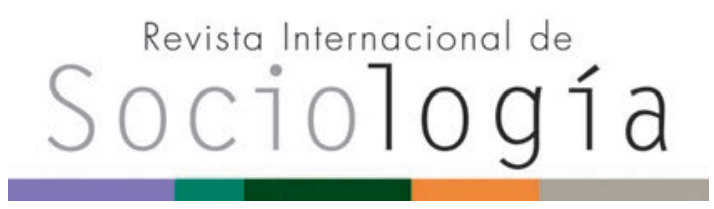

Revista Internacional de Sociología RIS vol. 76 (2), e098, abril-junio, 2018, ISSN-L:0034-9712 https://doi.org/10.3989/ris.2018.76.2.16.159

\section{PERCEPCIÓN DE LA CALIDAD DE VIDA EN PRISIÓN. La importancia de una buena
organización y un trato digno}

JORGE RODRíguez MENÉs

Universitat Pompeu Fabra, España.

jorge.rodriguez@upf.edu

ORCID iD: https://orcid.org/0000-0001-5445-6319

\author{
ELENA LARRAURI PIJOAN \\ Universitat Pompeu Fabra, España. \\ elena.larrauri@upf.edu \\ ORCID iD: https://orcid.org/0000-0001-7556-3236
}

\author{
CRISTINA GÜERRI FERRÁNDEZ \\ Universitat Pompeu Fabra, España. \\ cristina.guerri@upf.edu \\ ORCID iD: https://orcid.org/0000-0002-4382-040X
}

Cómo citar este artículo / Citation: Rodríguez Menés, J., E. Larrauri Pijoan y C. Güerri Ferrández. 2018. "Percepción de la calidad de vida en prisión. La importancia de una buena organización y un trato digno". Revista Internacional de Sociología 76(2):e098. https:// doi.org/10.3989/ris.2018.76.2.16.159

\section{ResUmen}

Estudios previos sobre la vida en los centros penitenciarios españoles han tendido a hablar de 'la' prisión como una institución con condiciones de encarcelamiento uniformes. Sin embargo, la literatura internacional sugiere que la privación de libertad puede experimentarse de forma muy distinta según el centro penitenciario donde se cumpla condena. Esta investigación analiza si existen distintos tipos de prisión en España, a qué factores son debidas dichas diferencias, cuáles son más relevantes y cuáles son sus implicaciones.

Con esta finalidad, hemos administrado el cuestionario Measuring Quality of Prison Life a quinientos presos en cuatro centros penitenciarios de Barcelona. Los resultados de nuestro estudio muestran que la calidad de vida difiere significativamente entre las prisiones analizadas. Estas diferencias, que conllevan importantes consecuencias para las personas presas, no obedecen en exclusiva al historial del interno, sino también, o sobre todo, a la organización del centro y al sistema de relaciones interpersonales existente.

\section{Palabras Clave}

Autolesiones; Calidad de vida; Centros penitenciarios; Comportamiento penitenciario.

\section{PERCEPTION OF THE QUALITY OF LIFE IN PRISON. The importance of a good organization and decent treatment}

Copyright: (C) 2018 CSIC. Este es un artículo de acceso abierto distribuido bajo los términos de la licencia de uso y distribución Creative Commons Reconocimiento 4.0 Internacional (CC BY 4.0).

Recibido: 04/11/2016. Aceptado: 26/04/2017

\section{ABstract}

Existing studies about inmate's perception of prison conditions in Spain tend to refer to 'the' prison, as if all prisons were uniform institutions with similar life conditions. However, international research suggests that the experience of imprisonment is different depending on the prison in which the sentence is served.

To analyze this question, we have administered an adaptation to the Spanish context of the survey Measuring Quality of Prison Life in four prisons of Barcelona. Our findings suggest that quality of prison life is significantly different among prisons, that these differences have consequences for inmates' wellbeing, and that most of those differences are due to organization and personal relations and not mainly to inmates' individual characteristics.

\section{KEYWORDS}

Prison behavior; Prison; Quality of life; Self-harm. 


\section{INTRODUCCIÓN}

La finalidad de este estudio es avanzar en el conocimiento sociológico y criminológico de la prisión. Nos interesa especialmente: a) constatar si existen o no diferencias entre prisiones en lo que respecta a la 'calidad de vida' de los presos; b) averiguar a qué factores son debidas dichas diferencias; c) destacar cuáles son los más relevantes para explicarlas; y d) explorar qué consecuencias comportan para los internos.

A nuestro juicio, estos objetivos representan un avance respecto al actual estado de la discusión en España, por dos motivos. Por un lado, cubren una laguna en los estudios sobre prisiones, al abordar aspectos poco explorados hasta el momento. Lo que más ha preocupado a los académicos ha sido, por buenas razones, el crecimiento de las tasas de encarcelamiento (Díez-Ripollés 2006; Cid 2008; Becerra 2012; González 2012) y, desde 2008, su descenso (Forero y Jiménez 2014; Brandariz 2015; Dünkel 2017), sin detenerse en el análisis de las condiciones de vida de la prisión.

Por otro lado, las investigaciones originarias sobre las condiciones de vida en el interior de la prisión (Ríos y Cabrera 1998; Gallego et al. 2010) se han centrado en la calidad de vida en 'la' prisión. Nuestra investigación quiere demostrar, además, como sostienen diversos autores (Dilulio 1987; Downes 1988; Sparks y Bottoms 1995; Liebling 2004; Kruttschnitt y Dirkzwager 2011; Pratt y Eriksson 2012; Beyens y Boone 2015), que existen distintos tipos de prisión donde las condiciones del encarcelamiento conllevan unas consecuencias más o menos dañinas para las personas presas. Aunque una prisión 'no deja de ser una prisión', nuestro interés es descubrir qué hay detrás de afirmaciones tan comunes entre los presos como que una determinada prisión es, en su opinión, 'la peor'.

En una aproximación intuitiva a la explicación de los distintos climas sociales ${ }^{1}$ de una prisión se podría pensar que 'la peor prisión' es aquella que contiene un determinado perfil de internos. De esta forma, una prisión sería más o menos habitable en función de las características de sus presos. Si bien esta intuición es plausible, como demostraremos a lo largo de nuestro estudio, la calidad de vida de un centro penitenciario no depende fundamentalmente de quien habite la prisión, sino de las actividades que en ella se organicen y de las relaciones interpersonales que en ellas se desarrollen. Esta constatación tiene importancia para incorporar al análisis sociológico el tema de la gobernanza de las prisiones.

Esta aportación es tanto más necesaria por cuanto, como se verá más adelante, la distinta calidad de vida de las prisiones conlleva unas consecuencias más o menos dañinas para las personas presas (Liebling y Crewe 2012). Estas consecuencias, de nuevo, no se explican solo por las características perso- nales de los presos, sino fundamentalmente por la incidencia de la organización y de las relaciones que se establecen en las prisiones.

Para realizar esta investigación nos hemos servido del cuestionario Measuring Quality of Prison Life (en adelante, MQPL), desarrollado por el Prison Research Center del Instituto de Criminología de Cambridge, que permite medir la calidad de vida en prisión desde la perspectiva de las personas presas. Este cuestionario fue desarrollado después de numerosas entrevistas con los presos y persigue superar las evaluaciones oficiales que se fijan en indicadores objetivos (p. ej. número de programas y actividades, o número de fugas), en un intento de medir aquello que es 'más relevante' para la vida de los presos (Liebling 2004). Una novedad adicional de este cuestionario es que recoge no solo indicadores de rendimiento sino también preguntas con 'dimensiones morales' (Bennett 2007), que miden el trato que el personal de la prisión dispensa al colectivo de los presos. Por ello se afirma que pretende medir 'la calidad moral' (moral performance) de cada prisión.

Una vez traducido y adaptado al castellano, el cuestionario se administró a una muestra representativa de los internos de cuatro centros penitenciarios de hombres de la provincia de Barcelona, lo cual nos permitió constatar la diferente evaluación que realizan los presos de dichos centros. Pudiera darse el caso de que los resultados fueran distintos en centros penitenciarios de mujeres ya que, como ha mostrado una extensa literatura criminológica, las penalidades de las mujeres en prisión tienen características específicas (Rafter 1985; Bosworth 1999; Kruttschnitt y Gartner 2003; véanse referencias actualizadas en Almeda 2017). Sin embargo, por motivos de oportunidad, el estudio se limitó a prisiones de hombres ${ }^{2}$. En cualquier caso, creemos que nuestro trabajo proporciona una primera valoración de la calidad de vida en las prisiones españolas que, sin duda, habrá de ser complementada en el futuro con encuestas en otras prisiones.

\section{ESTADO DE LA DISCUSIÓN: ESTUDIOS SOBRE CALIDAD DE VIDA DE LA PRISIÓN}

Liebling (2004) identifica tres fases en el análisis de la prisión. En un primer momento los sociólogos fueron los primeros en interesarse por la prisión en cuanto organización social, dando lugar a trabajos etnográficos que buscaban describir y explicar la prisión, pero no evaluarla (por ejemplo, Clemmer 1940; Sykes 1958; Jacobs 1977).

En una segunda fase, liderada por los psicólogos, las investigaciones se centraron en cuestiones de tratamiento. El nombre clave en esta época es Moos (1968), quien midió el clima social de una prisión para intentar discernir su efecto terapéutico y evaluar los efectos de los distintos regímenes de vida en 
relación a consecuencias diversas (p. ej. el éxito en la libertad condicional).

La tercera etapa comienza con el declive de la ideología rehabilitadora y asume el objetivo de conseguir un 'confinamiento humano'. Esta fase coincide en el Reino Unido con la revolución gerencial, con un nuevo estilo de gobernanza dirigido a introducir la gerencia privada en el sector público para modernizar la organización del trabajo en las prisiones (Bennett 2007). Como parte de esta estrategia, el Prison Service desarrolló unos indicadores para evaluar las prisiones (King y McDermott 1995) que, en opinión de sus críticos, se han centrado más en medir 'lo medible' que 'lo relevante' (Liebling et al. 2011).

Para paliar estas deficiencias Liebling (2004) desarrolló un cuestionario a partir de las experiencias vividas por los presos y los funcionarios en prisión. A través de conversaciones individuales y grupales y de entrevistas semiestructuradas, se elaboró una lista con las dimensiones e ítems que, para los internos, eran determinantes en su percepción de calidad de vida y que configuraron la primera versión del MQPL. En opinión de esta autora, la variable clave que permite diferenciar a una prisión de otra es la calidad de las relaciones con el personal que trabaja en ella: el respeto, el trato imparcial y la falta de humillación en el trato hacia los presos tienen una gran relevancia para entender sus valoraciones de la vida en prisión. Las cárceles, para decirlo en palabras de Liebling (ibíd.), tienen distinta calidad moral, y esto a su vez conlleva distintas consecuencias, como índices de autolesiones y suicidios o tasas de reinserción distintos (Liebling 2006). Así fue como en el Reino Unido la evaluación de la prisión basada en la eficiencia pasó a completarse con 'indicadores morales' (Bennett 2007).

Para entender este énfasis en los indicadores morales es necesario apuntar tres influencias teóricas adicionales: a) las conclusiones de la comisión Woolf creada en Inglaterra en 1991 para explicar el porqué de los motines sucedidos en 1990, que apuntaban en gran parte al 'sentimiento de injusticia' imperante (Prison Reform Trust 1992); b) los estudios de Tyler (1999) acerca de la importancia de la legitimidad para conseguir la obediencia a las instituciones como los tribunales y la policía, a las que se añadieron las prisiones (Franke et al. 2010; Tyler 2010); y c) los estudios precursores de Sparks y Bottoms (1995) comparando dos tipos de prisiones en el Reino Unido para entender mejor cómo se mantiene el orden en ellas.

Probablemente sea cierto que esta cultura evaluadora se vio estimulada en el Reino Unido por la introducción de un plan de privatización de las prisiones y el interés en evaluar el cumplimiento de los objetivos pactados. Aun cuando en España no existan prisiones privadas, en nuestra opinión también tiene interés conocer qué rasgos convierten a una prisión en más so- portable que otra. Describir las condiciones de vida en el interior de las cárceles de un país permite compararlas entre sí no solo en función de la duración de la condena sino también de la severidad o 'la dureza' de las condiciones en las que se cumple (Downes 1988).

\section{NUESTRA INVESTIGACIÓN}

Como señalamos antes, los objetivos planteados en esta investigación son cuatro: a) constatar si existen o no diferencias entre prisiones en lo que respecta a la calidad de vida; b) averiguar a qué factores son debidas dichas diferencias; c) destacar cuáles de estos factores son los más relevantes para explicarlas; y d) explorar qué consecuencias comporta para los internos una distinta calidad de vida.

Para alcanzar estos objetivos, el Grupo de Investigación en Criminología y Sistema Penal de la Universitat Pompeu Fabra se planteó en 2013 utilizar la MQPL en el entorno penitenciario catalán. Después de traducir la encuesta y obtener los correspondientes permisos del Departament de Justícia de la Generalitat, se realizaron casi 500 encuestas, desde 2013 a 2016, en cuatro centros penitenciarios (en adelante, $\mathrm{CP}$ ) de la provincia de Barcelona.

\section{EL CUESTIONARIO}

El cuestionario utilizado en nuestra investigación contiene, además de una serie de preguntas de carácter sociodemográfico y penitenciario que nos permiten dibujar el perfil de cada interno, 46 de los 126 ítems de la encuesta MQPL original con los que se intentaba captar la opinión de los internos sobre distintos aspectos de su vida en prisión. Estos ítems fueron seleccionados con el asesoramiento del Instituto de Criminología de la Universidad de Cambridge de forma que la encuesta contuviera dos o tres preguntas de cada dimensión de la vida en prisión medida por la MQPL. Esta reducción fue necesaria porque, mientras que en Inglaterra y Gales las encuestas las autocompletan los internos, las nuestras fueron administradas por entrevistadores y cara a cara, para poder captar también las experiencias y opiniones de aquellos que no saben leer o tienen dificultades con el idioma ${ }^{3}$.

Estos 46 ítems recogen las opiniones y actitudes de los presos sobre aspectos organizativos y del sistema social de la prisión utilizando escalas Likert de cinco niveles, siguiendo la codificación original realizada por el equipo de Liebling en Cambridge para captar el grado de acuerdo con las afirmaciones leídas por el entrevistador. Sin embargo, para simplificar los análisis que mostraremos más adelante, los ítems han sido recodificados en variables binarias donde el 1 corresponde a una valoración positiva del aspecto de la prisión evaluado y el 0 a una valoración negativa o indiferente ${ }^{4}$. 
Para concluir el cuestionario, se pide al interno que puntúe la calidad de vida en prisión de 0 a 10 , entendiendo por tal las condiciones de vida y el trato que recibe en general. Esta pregunta será la variable dependiente de nuestra investigación, siendo nuestro objetivo el de comprobar si hay diferencias entre prisiones en la valoración media que los internos perciben de esta calidad.

\section{Operacionalización de LAS DIMENSIONES DE LA CALIDAD DE VIDA EN PRISIÓN}

Según la experiencia proporcionada por nuestras entrevistas y por otros estudios previos sobre calidad de vida (Downes 1988; Logan 1992; Kruttschnitt y Dirkzwager 2011; Pratt y Eriksson 2012), decidimos agrupar los ítems y preguntas de nuestro cuestionario en tres dimensiones y varias subdimensiones que consideramos como las más relevantes para explicar la calidad de vida en los centros penitenciarios catalanes. A continuación, describimos estas tres dimensiones y sus subdimensiones, así como los ítems y preguntas de la encuesta utilizados para medirlas, y que aparecen listados en la Tabla 1.

\section{1) Historial del interno}

Una de las constantes en la literatura de prisiones al discutir los valores culturales de los presos es hasta qué punto surgen en la prisión como respuesta a una problemática planteada por la estructura y el contexto carcelario (Clemmer 1940; Sykes 1958) o si, por el contrario, son un reflejo de los valores que la persona tiene en el exterior e importa al entrar en prisión (Irwin y Cressey 1962; Jacobs 1977). Un reflejo de esta discusión es hasta qué punto la prisión causa determinados males o si por el contrario las personas que entran en prisión ya son vulnerables previamente a los mismos. Así, por ejemplo, como es reconocido, en prisión hay un porcentaje muy alto de personas con enfermedad mental o enfermedades físicas (González 2012; Gallizo 2013) y lo que se discute precisamente es la contribución de la prisión en la causación de este estado (Liebling y Maruna 2005; Liebling, 2006; Crewe 2007; Dâmboeanu y Nieuwbeerta 2016).

Para intentar apreciar el historial con el cual el interno llega a la prisión hemos tomado en consideración:

i) Variables sociodemográficas: edad y nacionalidad.

ii) Salud mental: consumo de drogas, comportamientos autolesivos o internamiento en instituciones psiquiátricas previos al ingreso en prisión.

iii) Historial penológico (condena): si el interno es primario o reincidente, cuál es la duración de su condena y el tiempo que ha pasado en prisión a lo largo de su vida.

\section{2) Organización de la prisión}

Parece una obviedad señalar que una cárcel se experimenta de forma más o menos dura en función de los estándares de vida en su interior, las actividades que se realizan y los tratamientos y asesoramientos recibidos para ayudar a la reinserción.

iv) Condiciones materiales y estándar de vida: recoge la valoración de los internos de la higiene y el aseo, la atención médica y la alimentación proporcionados por el centro penitenciario. Las condiciones de higiene general de los módulos, la celda (por ejemplo, individual o compartida, con o sin ducha en el interior), la alimentación y la atención sanitaria son servicios básicos que deben ser suministrados sea cual sea la filosofía penitenciaria que uno acoja.

v) Actividades: una cárcel se experimenta como 'almacén' cuando se programan pocas actividades. Estas no tienen por qué tener necesariamente un carácter terapéutico ya que, en cualquier caso, cubren una necesidad humana básica como es la de realizar alguna tarea útil (Logan 1992). En esta subdimensión consideramos el trabajo productivo en talleres, el trabajo de mantenimiento de la propia prisión y actividades como la escuela y el polideportivo, en contraposición al tiempo que los presos pasan sin hacer nada en el patio.

vi) Tratamiento: la existencia de programas cognitivoconductuales incide en la vida del interno por diversos motivos: el preso puede valorar el programa porque siente que le ayuda a realizar un cambio positivo, porque piensa que con estos programas está más cerca de conseguir un permiso de salida, o porque valora la existencia de un espacio que le permite alejarse del patio o establecer relaciones positivas con los profesionales.

vii) Ayuda a la reinserción: a través de estas preguntas se refleja cómo el propio preso percibe que se le está ayudando a progresar a lo largo de su condena y a no delinquir en el futuro. Estos indicadores nos permiten averiguar si, en su opinión, la experiencia de la pena de prisión le sirve para alcanzar el fin de la reinserción social o si, por el contrario, experimenta su estancia en ella como una pérdida de tiempo.

\section{3) Relaciones interpersonales}

Como hemos explicado con anterioridad, la innovación más relevante del trabajo de Liebling (2004) ha sido situar al personal que trabaja en prisión como elemento clave de la vida en prisión y enfatizar la importancia primordial del trato humano que este dispensa a los presos.

viii) Relaciones con el personal: esta dimensión impregna la experiencia del preso porque, si se le trata con respeto, la persona puede llegar a pensar que en esta prisión 'no se está tan mal'. Los 
ítems de esta dimensión preguntan acerca del 'personal' de manera genérica a pesar de la evidente ambigüedad del término ${ }^{5}$.

ix) Relaciones con otros internos: las condiciones de vida están también marcadas por cómo se viven las relaciones con el resto de presos. Hay módulos más conflictivos en los que el preso puede sentir el temor constante de que sus bienes sean hurtados o el de verse inmerso en una pelea o conflicto y, en consecuencia, su experiencia de calidad de vida puede disminuir de forma muy significativa.

x) Relaciones con el exterior: un aspecto muy relevante para la vida de la persona presa es el acceso al teléfono y las visitas de los familiares. Así, la organización de estos contactos por parte de la dirección de un modo que los facilite influye decisivamente en la valoración de una prisión.

Tabla I.

Operacionalización de las dimensiones y subdimensiones.

\begin{tabular}{|c|}
\hline DIMENSIÓN 1: Historial del interno \\
\hline Subdimensión 1: Variables sociodemográficas \\
\hline Edad del interno (en años) \\
\hline Nacido en España \\
\hline Subdimensión 2: Salud mental \\
\hline El interno reporta que consumía drogas antes de ingresar en prisión \\
\hline El interno reporta un problema de abuso de drogas previo al ingreso prisión \\
\hline El interno reporta un problema de abuso de alcohol previo al ingreso en prisión \\
\hline Conducta autolesiva fuera de prisión \\
\hline Intento de suicidio fuera de prisión \\
\hline Ha estado internado en módulo/hospital psiquiátrico \\
\hline Subdimensión 3: Condena \\
\hline Primera vez en prisión \\
\hline Duración total de la condena (en años) \\
\hline Tiempo en prisión (en años) \\
\hline DIMENSIÓN 2: Organización de la prisión \\
\hline Subdimensión 4: Estándar de vida \\
\hline Se me suministra todo lo necesario para mantenerme limpio y aseado \\
\hline El personal me ayuda cuando tengo problemas médicos o de salud \\
\hline El interno considera que la comida no es una de las tres peores cosas de la prisión \\
\hline Subdimensión 5: Actividades \\
\hline No suelo pasar más de 6 horas sin actividades \\
\hline Esta prisión está bien organizada \\
\hline El interno participa en actividades educativas \\
\hline El interno tiene un puesto de trabajo (talleres y destinos) \\
\hline Subdimensión 6: Tratamiento \\
\hline Estoy realizando/he realizado un programa de tratamiento \\
\hline Recibió ayuda para desintoxicarse de las drogas cuando llegó a prisión \\
\hline Recibió ayuda para desintoxicarse del alcohol cuando llegó a prisión \\
\hline Subdimensión 7: Ayuda a la reinserción \\
\hline En esta prisión me ayudan a hacer planes para no delinquir cuando salga \\
\hline En general siento que estoy aprovechando el tiempo \\
\hline En esta prisión te explican qué has de hacer y te ayudan a progresar en grado \\
\hline DIMENSIÓN 3: Relaciones interpersonales \\
\hline Subdimensión 8: Con el personal \\
\hline El personal de esta prisión me trata con respeto \\
\hline Las relaciones entre el personal y los internos son buenas \\
\hline No siento miedo de que el personal me golpee/insulte/amenace \\
\hline Recibo apoyo del personal de esta prisión cuando lo necesito \\
\hline En esta prisión, el personal distribuye los destinos de forma justa \\
\hline Subdimensión 9: Con otros internos \\
\hline En este módulo no hay muchas peleas entre internos \\
\hline En esta prisión es difícil tener deudas \\
\hline En esta prisión no se tolera que unos internos acosen a otros \\
\hline Subdimensión 10: Con el exterior \\
\hline En esta prisión puedo recibir visitas con frecuencia \\
\hline El tiempo que se concede a una visita es suficiente \\
\hline Mantengo contacto frecuente con mi familia (visitas, correo, llamadas) \\
\hline
\end{tabular}




\section{Operacionalización de Los PROBLEMAS CONDUCTUALES}

Como hemos señalado, una vez detectados los factores que explican las diferencias entre los cuatro centros penitenciarios analizados y cuáles son los más relevantes para explicarlas, procederemos a estudiar las posibles consecuencias de dichas diferencias en calidad de vida sobre el comportamiento de los presos. Nos centraremos en tres problemas conductuales: a) intentos de suicidio, b) autolesiones y c) comportamientos objeto de sanciones graves (aislamiento en departamento especial) por el centro penitenciario. En los tres casos, la información es la suministrada por el mismo preso a preguntas directas formuladas por el entrevistador sobre la existencia de esos comportamientos durante la estancia en prisión.

\section{Muestra}

Los datos necesarios para llevar a cabo nuestra investigación se obtuvieron administrando la versión definitiva del cuestionario a 468 internos de los cuatro CP de hombres de la provincia de Barcelona ${ }^{6}$. Para seleccionar esta muestra, aplicamos un muestreo aleatorio estratificado por módulos que recogía aproximadamente un $10 \%$ de la población de cada módulo. La selección final de los internos se realizó por un método aleatorio simple con listas de sustitutos elegidos por el mismo procedimiento aleatorio.

De esta muestra inicial, hemos descartado las encuestas completadas por reclusos que se encontraban en módulos con regímenes de vida o condiciones de encarcelamiento especiales y, por lo tanto, poco representativas de la vida típica de la prisión en que se encontraban ${ }^{7}$, quedándonos con un total de 423 cuestionarios completados. Puesto que no todos los presos contestaron a todas las preguntas incluidas en nuestros análisis, el número de casos válidos quedó finalmente reducido a 327 internos.

En la Tabla II puede verse el tamaño de la muestra para cada prisión (tanto para la muestra original de 423 internos como para la final de 327), así como la población de los cuatro centros penitenciarios. Como puede observarse, el pequeño tamaño de las mues- tras, limitado por restricciones económicas, no permite realizar extrapolaciones para cada prisión con gran precisión (mucho menos a nivel de módulo). Así, la última columna de la tabla muestra que si la varianza de una proporción cualquiera que quisiéramos estimar fuera máxima $(p=q=.5)$, el margen de error de la estimación oscilaría entre un \pm 9 y un \pm 13 \% según la prisión, para un margen de confianza del 95 \%. Sin embargo, como mostraremos más adelante, pocas variables de las empleadas en la investigación presentaban una varianza tan extrema. Esto ha permitido detectar un buen número de efectos significativos y cumplir nuestro objetivo de explicar la calidad de vida en prisión con bastante precisión.

\section{TÉCNICAS DE ANÁLISIS}

Para alcanzar los objetivos de esta investigación, en primer lugar, realizaremos un análisis descriptivo con el que establecer las diferencias en la nota media que los internos han dado a la calidad de vida en cada prisión y en las valoraciones que hacen de las tres dimensiones que, conjeturamos más arriba, podrían explicarla. Esto nos permitirá constatar que estas diferencias, efectivamente, existen.

En segundo lugar, determinaremos si las diferencias en aquellas dimensiones ayudan a explicar las diferencias en la calidad de vida de los cuatro centros penitenciarios utilizando una regresión múltiple de mínimos cuadrados. En esta regresión, partiremos de un modelo inicial o "nulo" cuya variable dependiente será la calidad de vida y que contendrá, como única variable independiente, el centro penitenciario. En modelos sucesivos añadiremos paulatinamente las otras variables independientes que miden las tres grandes dimensiones (los historiales personales, las prácticas organizativas y las relaciones sociales de los internos de cada prisión) consideradas en la Tabla I. La estrategia de añadir variables en modelos sucesivos siempre más complejos busca establecer las inter-correlaciones existentes entre las variables independientes (especialmente, entre la prisión y las otras variables) mediante la observación del cambio en el efecto de cada una de ellas tras introducir las otras.

Tabla II.

Muestra por centro penitenciario.

\begin{tabular}{|l|c|c|c|c|c|c|c|}
\hline CP & Población & Muestra original & $\%$ & Margen de error* & Muestra final & $\%$ & Margen de error* $^{*}$ \\
\hline CP1 & 714 & 121 & $16,9 \%$ & $8,12 \%$ & 84 & $11,8 \%$ & $10,05 \%$ \\
\hline CP2 & 709 & 69 & $9,7 \%$ & $11,22 \%$ & 53 & $7,5 \%$ & $12,96 \%$ \\
\hline CP3 & 988 & 100 & $10,1 \%$ & $9,30 \%$ & 86 & $8,7 \%$ & $10,10 \%$ \\
\hline CP4 & 1296 & 133 & $10,3 \%$ & $8,05 \%$ & 104 & $8,0 \%$ & $9,22 \%$ \\
\hline Total & 3707 & 423 & $11,4 \%$ & $4,49 \%$ & 327 & $8,8 \%$ & $5,18 \%$ \\
\hline
\end{tabular}

*Suponiendo una varianza máxima ( $p=q=.5)$, con un margen de confianza del 95\% 
En tercer lugar, realizaremos una descomposición de la varianza de la calidad de vida en prisión explicada por cada dimensión (y subdimensión) para dilucidar la importancia neta relativa de cada una de ellas en esa explicación.

Por último, procederemos a comparar las notas medias en la calidad de vida en prisión de los presos con y sin problemas conductuales, para demostrar el impacto de aquella en estos comportamientos. Para investigar el grado en que estas diferencias se deben a la incidencia de los factores considerados en nuestro estudio explicativas de la calidad de vida en prisión, las compararemos con las que se podrían obtener utilizando los residuos generados en la regresión de la calidad de vida sobre todas las variables sociodemográficas, organizativas y relacionales consideradas antes. Finalmente, descontaremos el impacto que puede tener en la relación entre la calidad de vida y los problemas conductuales en prisión la posible predisposición de los presos hacia estas mismas conductas por motivo de haberlas padecido con anterioridad a la entrada en prisión.

\section{Resultados}

\section{Descripción de las diferencias en la percepción de calidad de vida entre prisiones}

Tal y como dijimos anteriormente, el primer objetivo de esta investigación es averiguar si hay diferencias en la calidad de vida percibida por los internos según la prisión en que se cumple la condena. Para medir dichas diferencias, hemos utilizado la pregunta en la que pedimos a los internos que puntúen el centro penitenciario en el cual se encuentran de 0 a 10 en términos de calidad de vida y hemos calculado la nota media que ha recibido cada prisión ${ }^{8}$.
Como puede observarse en el Gráfico 1, la nota media conjunta es relativamente alta (cercana al $5)$, lo cual puede parecer sorprendente teniendo en cuenta las condiciones de falta de libertad en que se encuentran los internos. Esto podría reflejar que, contrariamente a lo que a veces se asume, los presos son capaces de realizar juicios morales matizados y sus valoraciones son realistas y adecuadas a la realidad que les ha tocado vivir.

Asimismo, constatamos, tal y como ha destacado la literatura previa, que las diferencias entre prisiones existen. En este sentido, dos centros tienen valoraciones significativamente diferentes entre sí, el CP1 y el CP2, cuyos internos valoran la calidad de vida mejor y peor que la media, respectivamente.

Una primera duda que podría surgir es la de si estas diferencias se deben a la diferente composición de las prisiones, es decir, a que un perfil de interno sea más frecuente en una prisión que en otra (por ejemplo, porque hay una concentración de internos con condenas largas o reincidentes) y que ello dé lugar a valoraciones diferentes ${ }^{9}$.

En este sentido, dos prisiones destacan por tener perfiles más marcados y en gran medida opuestos entre sí: CP1 y CP2. El CP1 se caracteriza por tener un número muy elevado de internos no nacidos en España con pocos años servidos de prisión, con problemas poco importantes de adicción a las drogas y más importantes de adicción al alcohol. Por el contrario, los internos del CP2 tienden a ser españoles, con condenas largas, historiales delictivos reincidentes y un número mayor de años pasados en prisión, además de haber tenido problemas de adicción a las drogas (ver Gráfico A1 del Anexo para mayor detalle).

Gráfico 1.

Nota media según Centro Penitenciario.

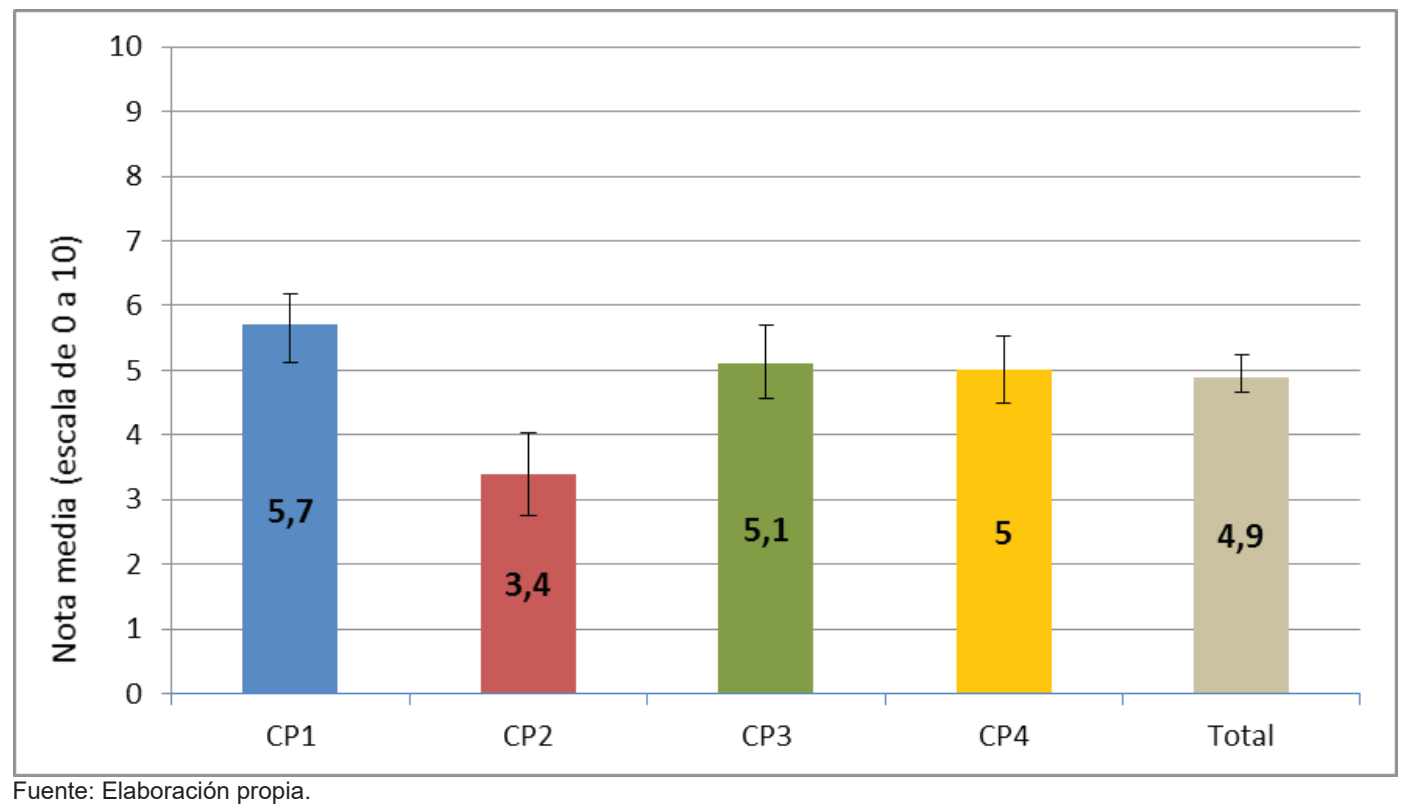

Fuente: Elaboración propia. 
Debido a que el CP2, que ha obtenido una nota inferior a la media, es el que reúne a un mayor número de internos con peor historial penal, y el CP1, con la mejor nota, es el que alberga internos que tienen un perfil significativamente mejor, podría ser que la diferencia en la evaluación de la calidad de vida en prisión se debiera exclusivamente a las características individuales del interno. No obstante, como veremos en el análisis de regresión múltiple, aun controlando por estos perfiles, las diferencias entre prisiones continúan siendo significativas, por lo que ya podemos anticipar que la distinta evaluación en las prisiones no responde exclusivamente a las diferencias en el perfil de sus internos.

En segundo lugar, resulta también interesante ver los resultados descriptivos para la dimensión 2 (Organización de la prisión). Vemos que, de nuevo, el CP1 destaca en un sentido positivo, teniendo valoraciones superiores a la media en las subdimensiones 4 (Estándar de vida) y 5 (Actividades), mientras que el CP2 muestra puntuaciones comparativamente pobres en la subdimensión 4 (Estándar de vida) y en la 7 (Ayuda a la reinserción). Respecto a la subdimensión 6 (Tratamiento) destaca la elevada variabilidad en la participación de los internos en programas de intervención según el centro penitenciario, realizándose más intervenciones en los CP3 y CP4 y menos en los CP1 y CP2 (ver Gráfico A2 del Anexo para mayor detalle).

En la dimensión 3 (Relaciones interpersonales), por el contrario, no se observan tantas diferencias. El CP1 sobresale por unas buenas relaciones con el personal y un trato más humano, mientras que en el CP2 se reporta cierto recelo hacia el personal, así como unas peores relaciones. Que las mejores relaciones con el personal sean destacadas por internos en la prisión con mejor nota media (y viceversa) puede ser un indicio de la preeminencia que estas tienen para medir el clima de una prisión. Finalmente, en la subdimensión 10 (Relaciones con el exterior) las respuestas de los internos sugieren que es más frecuente recibir visitas en el CP3 y que los internos del CP2 están menos satisfechos con el tiempo disponible para las visitas (ver Gráfico A3 del Anexo para mayor detalle).

Por lo tanto, vemos que, en general, el CP1 muestra puntuaciones más positivas en las variables que he- mos tomado en consideración mientras que el CP2 es valorado más negativamente. Los CP3 y CP4 se caracterizan por perfiles y valoraciones más heterogéneas.

A continuación, presentamos el análisis de regresión múltiple que nos permitirá ver la importancia que las distintas dimensiones y subdimensiones aquí consideradas tienen para explicar la nota media que han recibido las prisiones estudiadas.

\section{EXPLICACIÓN DE LAS DIFERENCIAS EN LA PERCEPCIÓN DE CALIDAD DE VIDA ENTRE PRISIONES}

Tras observar la evaluación que ha recibido cada prisión y las principales diferencias existentes entre estas en los distintos factores considerados, procedemos a investigar si las diferencias en la calidad de vida pueden explicarse por las diferencias en aquellos factores, mediante una regresión múltiple de mínimos cuadrados.

Las Tablas III, IV, V y VI que se presentan en las próximas páginas recogen los resultados principales de esta investigación. Cada modelo en las tablas muestra los coeficientes estimados como consecuencia de regresar la calidad de vida en prisión sobre un conjunto cada vez más amplio de variables independientes.

En la Tabla III mostramos el modelo "nulo" en el que se estiman las diferencias entre prisiones en la calidad de vida y que representa el punto de partida de nuestro análisis. En la Tabla IV investigamos si estas diferencias se deben a las habidas en el historial de los internos (Dimensión 1). En la Tabla $V$ analizamos cuánto de las diferencias entre prisiones en la calidad de vida, que no pudieron explicarse tras considerar los historiales de los internos, podrían deberse a la opinión que tienen los presos sobre la organización de la prisión (Dimensión 2). Por último, en la Tabla VI, analizamos cuánto de lo que quede por explicar de las diferencias entre prisiones tras introducir las variables anteriores podría deberse a la calidad de las relaciones interpersonales que mantienen dentro de sus muros y con el exterior (Dimensión 3 ).

Tabla III.

Análisis de regresión múltiple: Prisión (Modelo inicial o "nulo").

\begin{tabular}{|c|c|c|}
\hline & & Modelo 0 \\
\hline \multirow{3}{*}{ Prisión } & $\mathrm{X}_{1} \quad$ CP2 (Ref. CP1) & $-2,259^{* * *}$ \\
\hline & $\mathrm{X}_{2} \quad \mathrm{CP} 3$ (Ref. CP1) & $-0,527$ \\
\hline & $\mathrm{X}_{3} \quad \mathrm{CP} 4$ (Ref. CP1) & $-0,645$ \\
\hline \multicolumn{2}{|r|}{ Constante } & $5,655^{\star * *}$ \\
\hline & $\mathrm{R}^{2}$ Ajustado & $6,6 \%$ *** \\
\hline & Cambio en $\mathrm{R}^{2}$ Ajustado respecto al modelo anterior & - \\
\hline & R² Ajustado explicado por la variable "Prisión" & $6,6 \%$ *** \\
\hline & Cambio en $\mathrm{R}^{2}$ Ajustado explicado por la variable "Prisión" & - \\
\hline & Número de casos & 327 \\
\hline
\end{tabular}

RIS [online] 2018, 76 (2), e098. REVISTA INTERNACIONAL DE SOCIOLOGÍA. ISSN-L: 0034-9712 
Tal y como acabamos de señalar, partimos de un modelo inicial o "nulo" (Modelo 0 de la Tabla III) en el que incluimos como única variable independiente la prisión en la que se encuentra el interno. Ello nos permite observar las diferencias en cuanto a calidad de vida entre las cuatro prisiones que ya mostramos en el Gráfico 1, ahora mediante coeficientes de regresión. Estos expresan las diferencias en las notas medias otorgadas por los internos de los centros penitenciarios $\mathrm{CP} 2$, CP3 y CP4 en relación al $\mathrm{CP} 1$, que actúa como categoría de referencia ${ }^{10}$. Así, la nota media recibida por el CP1, al ser la prisión de referencia, está reflejada en la Tabla III por el valor de la constante $(5,66)$, mientras que los coeficientes de los otros centros penitenciarios nos muestran que el CP2 presenta una nota media 2,26 puntos significativamente inferior al CP1 y que los CP3 y CP4 obtienen respectivamente calificaciones medias 0,53 y 0,65 puntos inferiores al CP1, aunque en este caso las diferencias no son significativas ${ }^{11}$.

Un indicador de las diferencias globales entre prisiones y del peso que tienen para explicar por qué unos internos dan una nota más alta y otros más baja a su calidad de vida, puede encontrarse en la fila " $R^{2}$ Ajustado explicado por la variable 'Prisión"'12. Como vemos, el 6,65\% de la varianza o diferencias típicas en la calidad de vida de los internos puede explicarse por la variable 'prisión' y es estadísticamente significativo. Esperamos que en los sucesivos modelos que presentamos a continuación este valor llegue a ser muy cercano a 0 . Esto implicaría que hemos logrado explicar las diferencias entre prisiones haciendo referencia a los historiales típicos de los internos de cada prisión, a la organización que impera en cada una de ellas y a las relaciones sociales que emergen dentro de sus muros.

\section{Calidad de vida e historial del interno}

La Tabla IV muestra cuánto de las diferencias entre prisiones en la calidad de vida de los internos (Modelo 0) puede explicarse por las características sociodemográficas (Modelo 1), psicológicas referidas a salud mental (Modelo 2) o penológicas (Modelo 3 ) de los presos que componen cada prisión.

Tabla IV.

Análisis de regresión múltiple: Historial del interno (Dimensión 1).

\begin{tabular}{|c|c|c|c|c|c|c|}
\hline & & & & & & \\
\hline & & & Modelo 0 & Modelo 1 & Modelo 2 & Modelo 3 \\
\hline \multirow{3}{*}{\multicolumn{2}{|c|}{ Prisión }} & $\mathrm{X}_{1} \quad \mathrm{CP} 2$ (Ref. CP1) & $-2,259^{* * *}$ & $-2,135^{\star * *}$ & $-1,927^{\star * *}$ & $-1,624^{* * *}$ \\
\hline & & $\mathrm{X}_{2} \quad \mathrm{CP} 3$ (Ref. CP1) & $-0,527$ & $-0,406$ & $-0,267$ & $-0,179$ \\
\hline & & $\mathrm{X}_{3} \quad \mathrm{CP} 4$ (Ref. CP1) & $-0,645$ & $-0,613$ & $-0,445$ & $-0,385$ \\
\hline \multirow{11}{*}{ Historial } & \multirow{2}{*}{ Sociodemográfico } & $\mathrm{X}_{4} \quad$ Edad del interno (en años) & & $0,032^{*}$ & 0,024 & $0,029^{*}$ \\
\hline & & $X_{5} \quad$ Nacido en España & & $-0,814^{\star *}$ & $-0,610^{*}$ & $-0,514$ \\
\hline & \multirow{6}{*}{ Salud mental } & $\begin{array}{ll}\mathrm{X}_{6} & \begin{array}{l}\text { Consumo de drogas previo al ingreso en } \\
\text { prisión (Ref. No consumo) }\end{array}\end{array}$ & & & $-0,504$ & $-0,377$ \\
\hline & & $\begin{array}{l}\mathrm{X}_{7} \text { Abuso de drogas previo al ingreso en pri- } \\
\text { sión (Ref. No consumo) }\end{array}$ & & & $-0,747^{*}$ & $-0,511$ \\
\hline & & $\mathrm{X}_{8} \quad$ Abuso de alcohol previo al ingreso en prisión & & & 0,402 & 0,428 \\
\hline & & $\begin{array}{l}X_{9} \text { El interno se había autolesionado fuera de } \\
\text { la prisión }\end{array}$ & & & 0,343 & 0,327 \\
\hline & & $\begin{array}{l}\text { El interno había intentado suicidarse fuera } \\
X_{10} \text { de la prisión }\end{array}$ & & & $-0,257$ & $-0,189$ \\
\hline & & $\begin{array}{ll}\mathrm{X}_{11} & \text { Ha estado internado en módulo/hospital } \\
\text { psiquiátrico }\end{array}$ & & & $-0,542$ & $-0,562$ \\
\hline & \multirow{3}{*}{ Condena } & $\mathrm{X}_{12} \quad$ Primera vez en prisión & & & & 0,526 \\
\hline & & $\mathrm{X}_{13}$ Duración total de la condena (en años) & & & & $-0,013$ \\
\hline & & $\mathrm{X}_{14} \quad$ Tiempo en prisión (en años) & & & & $-0,076$ \\
\hline & & Constante & $5,655^{\star * *}$ & $4,814^{\star \star \star}$ & $5,245^{\star * *}$ & $4,874^{* * *}$ \\
\hline & & $\mathrm{R}^{2}$ Ajustado & $6,6 \%$ *** & $9,2 \% * * *$ & $9,7 \%$ *** & $10,9 \%$ *** \\
\hline & & $\begin{array}{l}\text { Cambio en R2 Ajustado respecto al modelo an- } \\
\text { terior }\end{array}$ & - & $2,6 \% *$ & $0,5 \%$ & $1,2 \%$ \\
\hline & & \multirow{2}{*}{$\begin{array}{l}\mathrm{R}^{2} \text { Ajustado explicado por la variable "Prisión" } \\
\text { Cambio en } \mathrm{R}^{2} \text { Ajustado explicado por la variable } \\
\text { "Prisión" }\end{array}$} & $6,6 \%$ *** & $6,0 \% * * *$ & $4,9 \%$ *** & $3,1 \%$ ** \\
\hline & & & - & $0,6 \%$ & $1,1 \%$ & $1,8 \%$ \\
\hline & & Número de casos & 327 & 327 & 327 & 327 \\
\hline
\end{tabular}

${ }^{*} p<0,05,{ }^{* *} p<0,01,{ }^{* * *} p<0,001$ 
Aunque el efecto de las dos variables introducidas en el Modelo 1 sobre la calidad de vida de los presos es significativo (los jóvenes y los nativos son los que perciben la prisión en peores términos), observamos que aportan poco a la explicación de las diferencias en calidad de vida entre prisiones (el poder explicativo de la prisión disminuye únicamente un 0,6\%, tras incorporar los perfiles sociodemográficos de los internos, tal y como aparece reflejado en la última fila de la Tabla IV, y que lleva por título "Cambio en el $R^{2}$ ajustado correspondiente a la prisión"). Para comprender mejor estos resultados, recuérdese que el Gráfico A1 en el Anexo solo detectó una mayor proporción de extranjeros en el CP1, lo que podría explicar en parte la mejor valoración de la calidad de vida en este centro, aunque no detectó diferencias significativas en la edad típica.

El impacto de los indicadores de salud mental añadidos en el Modelo 2 sobre la calidad de vida es algo mayor (genera una reducción en torno al 1,1 \% en las diferencias entre prisiones) a pesar de que la única variable que resulta significativa (y con un impacto negativo sobre la calidad de vida) es que el interno haya reportado que tenía un problema de abuso con las drogas previo al ingreso en prisión. Esto se explica en parte porque en el CP1 hay muchos menos internos que habían consumido drogas antes de ingresar en prisión (véase el Gráfico A1 del Anexo). Nótese que el impacto de la edad deja de ser significativo y el de la nacionalidad pasa a ser menos negativo cuando se tienen en cuenta problemas de adicción a las drogas, indicando que este tipo de problemas se concentran entre los jóvenes y los nativos.

Cuando añadimos el historial penológico del reo en el Modelo 3, las diferencias entre prisiones se reducen, de nuevo, significativamente $(1,8 \%)$. La bajada más acentuada se produce en el coeficiente del CP2, corroborando los resultados que mostraban que en dicho centro hay más internos que ya han estado en prisión, por más años y con condenas más largas que en las otras prisiones. Aunque ninguno de estos factores llega a tener un efecto significativo sobre la percepción de la calidad de vida, los coeficientes sugieren que tienen una influencia negativa sobre ella. Asimismo, el hecho de que el impacto negativo que la adicción a las drogas tiene en la calidad de vida deje de ser significativamente negativo al agregar el historial penal del reo sugiere que los adictos tienen más probabilidades de haber sido condenados más veces a prisión. También el impacto negativo de no haber nacido en España deja de ser significativo, implicando que dicho efecto se confundía con el efecto positivo de ser delincuente primario, que es más frecuente en los inmigrantes (véase el gráfico $A 1$ en el Anexo). Por último, el coeficiente de la edad aumenta y deviene de nuevo significativo porque los internos que van por primera vez a prisión tienden a ser más jóvenes.
A pesar de que las variables de la Dimensión 1 correspondientes al "Historial del interno" han reducido las diferencias entre prisiones en calidad de vida, estas persisten (ver $\mathrm{R}^{2}$ ajustado de la prisión en Tabla IV) y, por lo tanto, no es posible afirmar que la peor puntuación recibida por una prisión se deba exclusivamente al peor perfil de los internos que en ella cumplen condena.

\section{Calidad de vida y organización de la prisión}

En los Modelos 4 a 7 que se muestran en la Tabla $\checkmark$ evaluamos cuánto de lo que queda por explicar de las diferencias entre prisiones, tras considerar el historial de los internos, puede atribuirse a las opiniones de estos sobre cómo está organizada la vida en la prisión. En concreto analizamos en modelos sucesivos el impacto del estándar de vida (Modelo 4 ), las actividades que se programan (Modelo 5), los tratamientos que se ofertan (Modelo 6) y la ayuda a la reinserción que reciben los presos en cada prisión (Modelo 7).

El Modelo 4 muestra unos efectos fuertes (positivos) y significativos sobre la calidad de vida de los internos en relación a la opinión que estos tienen respecto a la higiene y las posibilidades de aseo que el centro penitenciario les proporciona y, en especial, de los cuidados médicos que reciben. Al considerar esta subdimensión, se hace más negativo el efecto que tener un problema de drogas tenía en la calidad de vida de los internos en el Modelo 3 de la Tabla IV (también reproducido en la primera de columna de la Tabla V), el cual vuelve a ser significativo porque los servicios médicos que reciben por su adicción incrementan su calidad de vida (esto también se aplica a quienes tienen un problema con el alcohol).

Las diferencias entre prisiones en esta subdimensión explican más de la mitad de las diferencias que quedaban por explicar tras considerar el historial de los internos (el efecto de la 'Prisión' pasa de un 3,09 $\%$ a un $1,4 \%$ ). Esta fuerte reducción se debe no solo al elevado impacto que tienen las variables de esta subdimensión sobre la calidad de vida, sino también a lo acentuadas que son las diferencias en la percepción de estos estándares entre las prisiones, especialmente entre el CP1 (más altos) y el CP2 (más bajos) (véase el Gráfico A2 en el Anexo).

El Modelo 5 añade información sobre cómo valoran los internos la organización de las actividades en su centro penitenciario. Cuanto más tiempo ocupan los internos en actividades diversas (especialmente, si trabajan en talleres o destinos ${ }^{13}$ ) y mejor organizada creen que está la vida en prisión, mejor perciben las condiciones en que cumplen su condena.

Con la introducción de estas variables las diferencias entre el CP1 y el CP2 desaparecen (dejan de ser significativas y ya no volverán a serlo en ningún otro modelo posterior) debido a que, como puede 
Tabla V.

Análisis de regresión múltiple: Organización de la prisión (Dimensión 2).

\begin{tabular}{|c|c|c|c|c|c|c|c|}
\hline & \\
\hline & & & Modelo 3 & Modelo 4 & Modelo 5 & Modelo 6 & Modelo 7 \\
\hline \multirow{3}{*}{\multicolumn{2}{|c|}{ Prisión }} & $\mathrm{X}_{1} \quad \mathrm{CP} 2$ (Ref, CP1) & $-1,624^{\star * *}$ & $-1,101^{*}$ & $-0,826$ & $-0,777$ & $-0,654$ \\
\hline & & $\mathrm{X}_{2}$ CP3 (Ref, CP1) & $-0,179$ & 0,071 & 0,531 & 0,479 & 0,343 \\
\hline & & $\mathrm{X}_{3}$ CP4 (Ref, CP1) & $-0,385$ & $-0,122$ & 0,542 & 0,42 & 0,266 \\
\hline \multirow{8}{*}{ Historial } & \multirow{2}{*}{ Sociodemográfico } & $\mathrm{X}_{4} \quad$ Edad del interno (en años) & $0,029^{*}$ & 0,01 & 0,006 & 0,007 & 0,01 \\
\hline & & $X_{5}$ Nacido en España & $-0,514$ & $-0,242$ & 0,287 & 0,289 & 0,262 \\
\hline & \multirow{6}{*}{ Salud mental } & $\begin{array}{ll}\mathrm{X}_{6} & \text { Consumo de drogas previo al ingreso } \\
\text { en prisión (Ref, No consumo) }\end{array}$ & $-0,377$ & $-0,197$ & 0,103 & 0,177 & 0,153 \\
\hline & & $\begin{array}{l}\mathrm{X}_{7} \text { Abuso de drogas previo al ingreso en } \\
\text { prisión (Ref, No consumo) }\end{array}$ & $-0,511$ & $-0,706^{*}$ & $-0,311$ & $-0,274$ & $-0,404$ \\
\hline & & $\begin{array}{l}\mathrm{X}_{8} \begin{array}{l}\text { Abuso de alcohol previo al ingreso en } \\
\text { prisión }\end{array}\end{array}$ & 0,428 & 0,383 & 0,177 & 0,338 & 0,538 \\
\hline & & $\begin{array}{l}\text { El interno se había autolesionado fuera } \\
\text { de la prisión }\end{array}$ & 0,327 & 0,519 & $0,994^{*}$ & $1,011^{*}$ & $1,053^{*}$ \\
\hline & & $\begin{array}{l}\text { El interno había intentado suicidarse } \\
X_{10} \text { fuera de la prisión }\end{array}$ & $-0,189$ & 0,069 & $-0,068$ & $-0,103$ & $-0,333$ \\
\hline & & $\begin{array}{l}\text { Ha estado internado en módulo/hospi- } \\
\mathrm{X}_{11} \text { tal psiquiátrico }\end{array}$ & $-0,562$ & $-0,68$ & $-0,466$ & $-0,448$ & $-0,257$ \\
\hline \multirow{16}{*}{$\begin{array}{l}\text { Organi- } \\
\text { zación }\end{array}$} & \multirow{3}{*}{ Condena } & $\mathrm{X}_{12}$ Primera vez en prisión & 0,526 & 0,381 & 0,251 & 0,234 & 0,11 \\
\hline & & $X_{13}$ Duración total de la condena (en años) & $-0,013$ & $-0,012$ & $-0,009$ & $-0,007$ & $-0,002$ \\
\hline & & $\mathrm{X}_{14}$ Tiempo en prisión (en años) & $-0,076$ & $-0,076$ & $-0,058$ & $-0,064$ & $-0,074^{*}$ \\
\hline & \multirow{3}{*}{ Estándar de vida } & $\begin{array}{ll}X_{15} & \text { Se me suministra todo para mantener- } \\
\text { me limpio y aseado }\end{array}$ & & $0,778^{* *}$ & $0,601^{*}$ & $0,637^{*}$ & 0,464 \\
\hline & & $\begin{array}{l}\text { El personal me ayuda cuando tengo } \\
\mathrm{X}_{16} \text { problemas médicos o de salud }\end{array}$ & & $1,800^{* * *}$ & $1,280^{* * *}$ & $1,265^{\star * *}$ & $0,902^{* * \star}$ \\
\hline & & $\begin{array}{l}\mathrm{X}_{17} \text { La comida no es mala (no es una de } \\
\text { las peores cosas de la prisión) }\end{array}$ & & 0,002 & 0,035 & 0,039 & 0,091 \\
\hline & \multirow{4}{*}{ Actividades } & $\begin{array}{l}\text { No suelo pasar más de } 6 \text { horas sin ac- } \\
\mathrm{X}_{18} \text { tividades }\end{array}$ & & & $1,082^{* * *}$ & $1,085^{* * *}$ & $0,953^{* * *}$ \\
\hline & & $\mathrm{X}_{19}$ Esta prisión está bien organizada & & & $1,816^{* * *}$ & $1,813^{* * *}$ & $1,417^{* * *}$ \\
\hline & & $\mathrm{X}_{20}$ Actividades educativas & & & 0,189 & 0,211 & 0,282 \\
\hline & & $\mathrm{X}_{21}$ Trabajo (talleres $\mathrm{y}$ destinos) & & & $0,642^{*}$ & $0,684^{*}$ & $0,651^{*}$ \\
\hline & \multirow{3}{*}{ Tratamiento } & $\begin{array}{l}\text { Estoy realizando/he realizado un pro- } \\
\mathrm{X}_{22} \text { grama de tratamiento }\end{array}$ & & & & 0,238 & 0,268 \\
\hline & & $\begin{array}{ll}X_{23} & \text { Recibió ayuda para desintoxicarse de } \\
& \text { las drogas cuando llegó a prisión }\end{array}$ & & & & $-0,071$ & $-0,111$ \\
\hline & & $\begin{array}{l}\text { Recibió ayuda para desintoxicarse del } \\
\mathrm{X}_{24} \text { alcohol cuando llegó a prisión }\end{array}$ & & & & $-0,336$ & $-0,369$ \\
\hline & \multirow{3}{*}{$\begin{array}{l}\text { Ayuda a la } \\
\text { reinserción }\end{array}$} & $\begin{array}{l}\text { En esta prisión me ayudan a hacer pla- } \\
\mathrm{X}_{25} \text { nes para no delinquir cuando salga }\end{array}$ & & & & & $0,906^{\star * *}$ \\
\hline & & $\begin{array}{ll}\mathrm{X}_{26} & \text { En general siento que estoy aprove- } \\
\text { chando el tiempo }\end{array}$ & & & & & $0,555^{*}$ \\
\hline & & $\mathrm{X}_{27}$ En esta prisión te explican qué has de $\mathrm{y}$ te ayudan a progresar en grado & & & & & $0,687^{* *}$ \\
\hline & & Constante & $4,874^{* * *}$ & $3,834^{\star * *}$ & $1,703^{*}$ & $1,530^{*}$ & 1,137 \\
\hline & & $\mathrm{R}^{2}$ Ajustado & $10,9 \%$ *** & $24,5 \%$ *** & $40,9 \%$ *** & $40,6 \%$ *** & $47,1 \%$ *** \\
\hline & & $\begin{array}{l}\text { Cambio en } R^{2} \text { Ajustado respecto al modelo } \\
\text { anterior }\end{array}$ & $1,2 \%$ & $13,6 \% * * *$ & $16,4 \% * * *$ & $-0,3 \%$ & $6,5 \%$ *** \\
\hline & & $\begin{array}{l}\mathrm{R}^{2} \text { Ajustado explicado por la variable "Pri- } \\
\text { sión" }\end{array}$ & $3,1 \%$ ** & $1,4 \% *$ & $2,7 \%$ ** & $1,8 \% *$ & $0,9 \% *$ \\
\hline & & $\begin{array}{l}\text { Cambio en } \mathrm{R}^{2} \text { Ajustado explicado por la va- } \\
\text { riable "Prisión" }\end{array}$ & $1,8 \%$ & $1,7 \%$ & $-1,3 \%$ & $0,9 \%$ & $0,9 \%$ \\
\hline & & Número de casos & 327 & 327 & 327 & 327 & 327 \\
\hline
\end{tabular}


verse en el gráfico A2 del Anexo, las diferencias en la calidad de vida entre estas prisiones se deben en buena parte a la, respectivamente, mejor y peor evaluación que los presos hacen de la programación de actividades de su prisión. Sin embargo, como puede observarse en la tabla, las diferencias globales entre centros penitenciarios aumentan (el peso de la variable 'Prisión' pasa a explicar un $2,74 \%$ de la varianza en la calidad de vida de los internos), en vez de disminuir como cabría esperar al ir explicando las diferencias. Este aumento es debido a que las diferencias entre los centros CP3 y CP4, respecto del CP1 se han acrecentado.

Dicho en otras palabras, en los centros CP2, CP3 y CP4 la programación de actividades es peor que en el CP1. De hecho, si se ignorase esta subdimensión (además del hecho de tener internos con peores historiales, como vimos antes), en el CP3 y CP4 se observaría una calidad de vida mayor que en los otros dos centros, estadísticamente significativa solo respecto al CP2.

El Modelo 6 añade la subdimensión de tratamiento, la cual incluye la participación de los internos en programas de intervención estructurados y de ayuda para desintoxicarse de las drogas o el alcohol. Quizás de forma inesperada, participar en programas de intervención no tiene un impacto estadísticamente significativo en la calidad de vida reportada por los internos, como tampoco el haber recibido ayuda para desintoxicarse.

Sin embargo, las diferencias entre prisiones se reducen al introducir este bloque de variables de forma conjunta, indicando que, globalmente, sí tienen un impacto significativo sobre la calidad de vida en prisión. Esta reducción del 2,7 \% al 1,8 \% puede ser explicada por la gran diferencia en la participación en programas de tratamiento estructurados entre centros penitenciarios que vimos en el análisis de los datos descriptivos.

Por último, el Modelo 7 valora la subdimensión "ayuda a la reinserción". Todas las variables añadidas con este modelo (percepción de que se está aprovechando el tiempo de condena, de que se recibe ayuda para progresar en grado y para planificar una vida en libertad) tienen un efecto significativo y positivo sobre la calidad de vida en prisión. Considerar la ayuda a la reinserción reduce aún más las diferencias entre prisiones (la varianza explicada por la prisión pasa del 1,8\% al 0,9\%), aunque de forma menos pronunciada de lo que podríamos esperar dada la significación mostrada por las variables de esta subdimensión, probablemente porque la mayor parte de sus efectos se materializan a través de otras variables ya introducidas antes. En este sentido, se observa cómo al introducir las variables de dicha subdimensión, los efectos positivos de las subdimensiones 4 (Estándar de vida) y 5 (Actividades) sobre la calidad de vida en prisión pierden fuerza, porque los centros penitenciarios que mejor ayudan a la reinserción son también los que más destacan en dichas subdimensiones.

\section{Calidad de vida y relaciones interpersonales}

La Tabla VI se focaliza en la tercera dimensión considerada para explicar la distinta evaluación de las prisiones, esto es, las relaciones interpersonales de los internos.

El Modelo 8 se centra concretamente en la subdimensión "relaciones entre los internos y el personal". Muestra que cuanto más respetuoso es el trato del funcionario con el preso, mejor percibe este su calidad de vida en prisión.

Este trato parece ser una consecuencia de (o, por lo menos, lleva aparejada) una buena organización de la prisión $\left(\mathrm{X}_{18}\right)$ y la participación del preso en sus actividades $\left(\mathrm{X}_{19}\right)$, así como un buen asesoramiento a los presos para que puedan progresar en grado $\left(X_{27}\right)$, pues los efectos positivos de dichas variables se reducen al tener en cuenta las relaciones con los funcionarios.

El Modelo 9 introduce las variables consideradas en la subdimensión "relaciones entre los internos". Todas tienen un impacto positivo y significativo sobre la calidad de vida de los internos, destacando el que se produce cuando no existen problemas por deudas entre internos.

Finalmente, el Modelo 10 considera las relaciones de los internos con el exterior y muestra que estos reportan una mejor calidad de vida cuando perciben que el centro penitenciario facilita que reciban visitas con frecuencia.

Muchos de los efectos de las variables introducidas en esta Dimensión 3 (relaciones interpersonales) son significativos para la calidad de vida de los internos en prisión, pero tienen poco impacto sobre las diferencias entre prisiones (la varianza explicada por la prisión solo aumenta ligeramente), en parte porque quedan pocas diferencias por explicar y en parte porque mucho del efecto de las variables relacionales no puede separarse del de las otras.

A pesar de no ayudar a explicar mejor las diferencias en calidad de vida entre prisiones, la introducción de las variables correspondientes al contacto del interno con el exterior sí afectan al impacto de otras variables sobre la calidad de vida. Así, aquellos que han tenido problemas de alcoholismo valoran aún mejor la calidad de vida al controlar por las variables de contacto con el exterior, sugiriendo que quienes más problemas con el alcohol padecen son los que menos visitas reciben, y esto baja su percepción de la calidad de vida (es decir, si no fuera por esto, estarían aún más satisfechos con su vida en prisión). Otra consecuencia destacable es que se reduce algo el impacto que sobre la calidad de vida tiene la per- 
Tabla VI.

Análisis de regresión múltiple: Relaciones interpersonales (Dimensión 3).

\begin{tabular}{|c|c|c|c|c|c|c|}
\hline & & & & & & \\
\hline & & & Modelo 7 & Modelo 8 & Modelo 9 & Modelo 10 \\
\hline \multirow{3}{*}{\multicolumn{2}{|c|}{ Prisión }} & $\mathrm{X}_{1} \quad \mathrm{CP} 2$ (Ref, CP1) & $-0,654$ & $-0,639$ & $-0,615$ & $-0,600$ \\
\hline & & $\mathrm{X}_{2} \quad \mathrm{CP} 3$ (Ref, CP1) & 0,343 & 0,386 & 0,478 & 0,497 \\
\hline & & $\mathrm{X}_{3} \quad \mathrm{CP} 4$ (Ref, CP1) & 0,266 & 0,302 & 0,388 & 0,498 \\
\hline \multirow{11}{*}{ Historial } & \multirow{2}{*}{$\begin{array}{l}\text { Sociodemo- } \\
\text { gráfico }\end{array}$} & $\mathrm{X}_{4} \quad$ Edad del interno (en años) & 0,010 & 0,002 & $-0,002$ & 0,004 \\
\hline & & $\mathrm{X}_{5} \quad$ Nacido en España & 0,262 & 0,225 & 0,190 & 0,186 \\
\hline & \multirow{6}{*}{ Salud mental } & $\mathrm{X}_{6} \quad$ Consumo de drogas previo al ingreso en prisión (Ref, No consumo) & 0,153 & 0,269 & 0,239 & 0,195 \\
\hline & & $\mathrm{X}_{7}$ Abuso de drogas previo al ingreso en prisión (Ref, No consumo) & $-0,404$ & $-0,254$ & $-0,294$ & $-0,143$ \\
\hline & & $\mathrm{X}_{8} \quad$ Abuso de alcohol previo al ingreso en prisión & 0,538 & 0,543 & 0,633 & $0,719^{*}$ \\
\hline & & $X_{9} \quad$ El interno se había autolesionado fuera de la prisión & $1,053^{*}$ & $1,056^{*}$ & $1,104^{\star *}$ & $1,100^{* *}$ \\
\hline & & $X_{10}$ El interno había intentado suicidarse fuera de la prisión & $-0,333$ & $-0,415$ & $-0,53$ & $-0,517$ \\
\hline & & $\mathrm{X}_{11}$ Ha estado internado en módulo/hospital psiquiátrico & $-0,257$ & $-0,039$ & 0,124 & 0,064 \\
\hline & \multirow{3}{*}{ Condena } & $\mathrm{X}_{12}$ Primera vez en prisión & 0,110 & 0,066 & $-0,047$ & $-0,087$ \\
\hline & & $\mathrm{X}_{13}$ Duración total de la condena (en años) & $-0,002$ & 0,009 & 0,009 & 0,013 \\
\hline & & $\mathrm{X}_{14}$ Tiempo en prisión (en años) & $-0,074^{*}$ & $-0,05$ & $-0,037$ & $-0,041$ \\
\hline \multirow{13}{*}{$\begin{array}{l}\text { Organiza- } \\
\text { ción }\end{array}$} & \multirow{3}{*}{$\begin{array}{l}\text { Estándar de } \\
\text { vida }\end{array}$} & $\mathrm{X}_{15}$ Se me suministra todo para mantenerme limpio y aseado & 0,464 & 0,391 & 0,275 & 0,314 \\
\hline & & $\mathrm{X}_{16}$ El personal me ayuda cuando tengo problemas médicos o de salud & $0,902^{* * *}$ & $0,701^{* *}$ & $0,693^{\star *}$ & $0,576^{*}$ \\
\hline & & $\mathrm{X}_{17}$ La comida no es mala (no es una de las 3 peores cosas de la prisión) & 0,091 & 0,167 & 0,263 & 0,288 \\
\hline & \multirow{4}{*}{ Actividades } & $\mathrm{X}_{18}$ No suelo pasar más de 6 horas sin actividades & $0,953^{* * *}$ & $0,790^{* *}$ & $0,690^{* *}$ & $0,620^{*}$ \\
\hline & & $\mathrm{X}_{19}$ Esta prisión está bien organizada & $1,417^{* * *}$ & $1,033^{* * *}$ & $0,885^{* * *}$ & $0,949^{* * *}$ \\
\hline & & $\mathrm{X}_{20}$ Actividades educativas & 0,282 & 0,274 & 0,201 & 0,315 \\
\hline & & $\mathrm{X}_{21}$ Trabajo (talleres y destinos) & $0,651^{*}$ & $0,579^{*}$ & $0,603^{*}$ & $0,784^{* *}$ \\
\hline & \multirow{3}{*}{ Tratamiento } & $\mathrm{X}_{22}$ Estoy realizando/he realizado un programa de tratamiento & 0,268 & 0,279 & 0,202 & 0,226 \\
\hline & & $\mathrm{X}_{23}$ Recibió ayuda para desintoxicarse de las drogas cuando llegó a prisión & $-0,111$ & $-0,265$ & $-0,21$ & $-0,349$ \\
\hline & & $\mathrm{X}_{24}$ Recibió ayuda para desintoxicarse del alcohol cuando llegó a prisión & $-0,369$ & $-0,379$ & $-0,415$ & $-0,579$ \\
\hline & \multirow{3}{*}{$\begin{array}{l}\text { Ayuda a la } \\
\text { reinserción }\end{array}$} & $\begin{array}{l}\mathrm{X}_{25} \text { En esta prisión me ayudan a hacer planes para no delinquir } \\
\text { cualga }\end{array}$ & $0,906^{\star * *}$ & $0,820^{* * *}$ & $0,806^{* * *}$ & $0,797^{\star \star *}$ \\
\hline & & $\mathrm{X}_{26}$ En general siento que estoy aprovechando el tiempo & $0,555^{*}$ & $0,550^{*}$ & $0,537^{*}$ & $0,489^{*}$ \\
\hline & & $\begin{array}{ll}\mathrm{X}_{27} & \text { En esta prisión te explican qué has de hacer } \mathrm{y} \text { te ayudan a } \\
\text { progresar en grado }\end{array}$ & $0,687^{* *}$ & 0,335 & 0,293 & 0,291 \\
\hline \multirow{13}{*}{ Relaciones } & \multirow{5}{*}{$\begin{array}{l}\text { Con el } \\
\text { personal }\end{array}$} & $\mathrm{X}_{28}$ El personal de esta prisión me trata con respeto & & $1,128^{* * *}$ & $1,029^{* * *}$ & $0,963^{* * *}$ \\
\hline & & $\mathrm{X}_{29}$ Las relaciones entre el personal y los internos son buenas & & 0,211 & 0,263 & 0,254 \\
\hline & & $\mathrm{X}_{30}$ No siento miedo de que el personal me golpee/insulte/amenace & & $0,629^{*}$ & $0,654^{* *}$ & $0,695^{* *}$ \\
\hline & & $\mathrm{X}_{31}$ Recibo apoyo del personal de esta prisión cuando lo necesito & & $-0,085$ & $-0,168$ & $-0,257$ \\
\hline & & $\mathrm{X}_{32}$ En esta prisión, el personal distribuye los destinos de forma justa & & $0,554^{*}$ & $0,553^{*}$ & 0,481 \\
\hline & \multirow{3}{*}{$\begin{array}{l}\text { Con otros } \\
\text { internos }\end{array}$} & $\mathrm{X}_{33}$ En este módulo hay pocas peleas entre internos & & & $0,464^{*}$ & $0,480^{*}$ \\
\hline & & $\mathrm{X}_{34}$ En esta prisión es poco frecuente tener deudas & & & $0,674^{* *}$ & $0,703^{* *}$ \\
\hline & & $\mathrm{X}_{35}$ En esta prisión no se tolera que unos internos acosen a otros & & & $0,538^{*}$ & $0,484^{*}$ \\
\hline & \multirow{5}{*}{$\begin{array}{l}\text { Con el } \\
\text { exterior }\end{array}$} & $\mathrm{X}_{36}$ En esta prisión puedo recibir visitas con frecuencia & & & & $0,707^{* *}$ \\
\hline & & $\mathrm{X}_{37}$ No aplicable (En esta prisión puedo recibir visitas con frecuencia) & & & & 0,985 \\
\hline & & $\mathrm{X}_{38}$ El tiempo que se concede a una visita es suficiente & & & & $-0,084$ \\
\hline & & $\mathrm{X}_{39}$ No aplicable (El tiempo que se concede a una visita es suficiente) & & & & 0,950 \\
\hline & & $\mathrm{X}_{40}$ Mantengo contacto con mi familia (visitas, correo, llamadas) & & & & 0,207 \\
\hline & & Constante & 1,137 & 0,340 & $-0,193$ & -1.123 \\
\hline & & $\mathrm{R}^{2}$ Ajustado & $47,1 \%$ *** & $51,8 \% * * *$ & $54,6 \%$ *** & $55,9 \%$ *** \\
\hline & & Cambio en $\mathrm{R}^{2}$ Ajustado respecto al modelo anterior & $6,5 \%$ *** & $4,7 \%$ *** & $2,8 \%$ *** & $1,3 \% * *$ \\
\hline & & $\mathrm{R}^{2}$ Ajustado explicado por la variable "Prisión" & $0,9 \% *$ & $1,0 \%$ * & $1,3 \%$ * & $1,4 \%$ * \\
\hline & & Cambio en $\mathrm{R}^{2}$ Ajustado explicado por la variable "Prisión" & $0,9 \%$ & $-0,1 \%$ & $-0,3 \%$ & $-0,1 \%$ \\
\hline & & Número de casos & 327 & 327 & 327 & 327 \\
\hline
\end{tabular}


cepción del interno acerca de una distribución justa de los destinos, puesto que la nota final puede explicarse también porque quienes más valoran este hecho son también los que más visitas reciben.

Hasta el momento hemos intentado explicar la distinta evaluación de la calidad de vida entre las cuatro prisiones analizando el peso que podían tener en esta evaluación los factores individuales, organizativos y relacionales. Como se ha podido observar, si en el Modelo 0 las diferencias entre prisiones explicaban casi el $7 \%$ de la varianza en la calidad de vida, en el Modelo 10 explican poco más de un $1 \%$. Es decir: con nuestro análisis hemos logrado explicar la mayor parte de las diferencias entre prisiones en lo que a calidad de vida se refiere ${ }^{14}$. En el siguiente apartado avanzaremos en nuestro análisis para dar respuesta a nuestro tercer objetivo, esto es, averiguar qué factores son más relevantes en la percepción de calidad de vida en prisión.

\section{ELEMENTOS MÁS RELEVANTES EN LA PERCEPCIÓN DE CALIDAD DE VIDA ENTRE PRISIONES}

Una vez determinado nuestro modelo de regresión de mínimos cuadrados para explicar la calidad de vida en prisión, tal y como la perciben los internos, a partir de tres dimensiones y diversas subdimensiones, nuestro objetivo es averiguar cuáles de estos elementos son más relevantes para los presos. Para ello, hemos calculado el efecto neto que tiene cada uno de ellos sobre la percepción de la calidad de vida a nivel individual ${ }^{15}$. Los resultados para cada una de estas agrupaciones se muestran en el Gráfico 2.

De esta descomposición se desprende que los factores organizativos son en nuestro análisis los que mayor impacto tienen para que el interno evalúe positivamente la calidad de vida en prisión: casi un $12 \%$ de la varianza explicada de la variable dependiente se explica por el efecto directo de la organización de la prisión. Entre estos efectos organizativos destacan la importancia de una buena programación de actividades $(4,9 \%)$ y una buena ayuda a la reinserción $(3,4$ \%) (ver subdimensiones 5 y 7 de la Tabla I).

Los factores relacionales aparecen en nuestros análisis como el segundo elemento más valorado, ya que por sí solos explican casi un $9 \%$ de la calidad de vida en prisión. Un trato digno por parte del personal parece ayudar especialmente a que la experiencia del encarcelamiento se viva mejor por parte de los internos $(3,7 \%)$, pero también son importantes unas buenas relaciones con otros internos (2,8\%).

Por último, los resultados apuntan a que las características individuales de los internos influyen muy poco, al menos de forma directa, en el momento de valorar la calidad de vida en prisión (su escaso efecto no es significativo). En definitiva, los internos que,

Gráfico 2.

Varianza explicada por cada una de las dimensiones y subdimensiones.

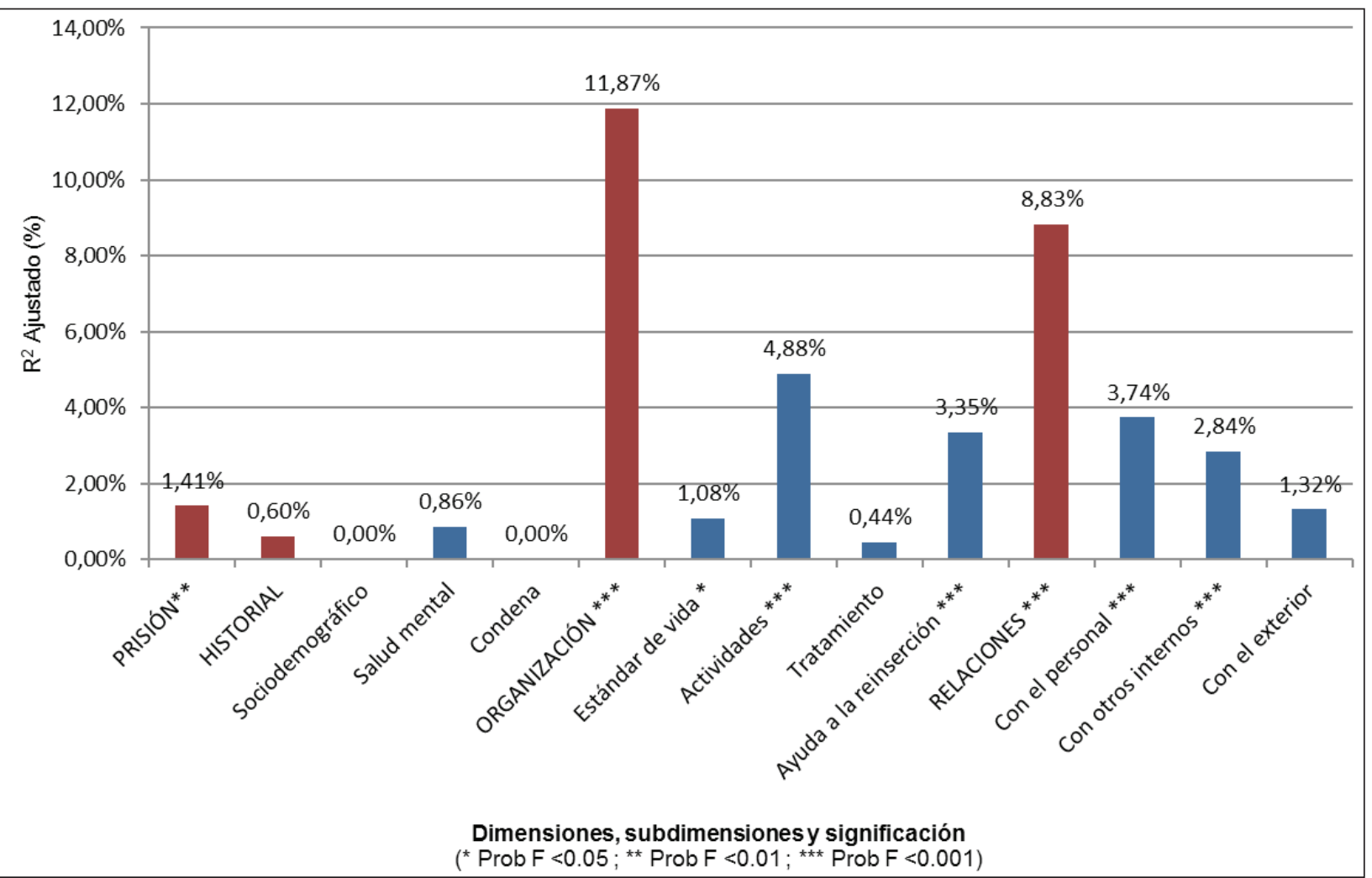

Fuente: Elaboración propia. 
entre otros factores, participan en actividades y reciben un buen trato por parte del personal y apoyo para su futura reinserción reportan una mejor calidad de vida en prisión, independientemente de sus características individuales.

\section{CONSECUENCIAS DE LA PERCEPCIÓN DE CALIDAD DE VIDAENTRE PRISIONES}

En este último apartado exploramos las posibles implicaciones que una mejor o peor calidad de vida tiene para las personas presas. En concreto, analizamos sus consecuencias sobre los problemas de conducta del interno en prisión. Nuestra hipótesis es que quienes evalúan peor la prisión serán los que más sufran la dureza de sus condiciones, lo que a su vez se manifestaría en comportamientos agresivos hacia ellos mismos u otros compañeros y hacia los funcionarios.

Para evaluar la plausibilidad de la hipótesis, hemos comparado la calidad de vida de los internos que dicen haber incurrido en comportamientos autolesivos o intentos de suicidio durante su encierro en prisión, o que dicen haber sido sancionados con faltas graves por sus comportamientos, con la de quienes no muestran estos comportamientos conflictivos.

Las primeras tres columnas de la Tabla VII muestran las notas medias otorgadas a la calidad de vida de la prisión, en una escala de 0 a 10, por aquellos internos que dicen haberse autolesionado o intentado suicidar, o haber sido sancionados con aislamiento en departamento especial por una falta grave estando en prisión, frente a aquellos que no lo hacen, así como la diferencias entre ambas medias. Como puede observarse, esta diferencia es significativa y en la dirección esperada de que quienes manifiestan haber tenido problemas conductuales importantes son también quienes peor evalúan la calidad de vida en prisión.

Las siguientes tres columnas muestran las mismas medias y diferencias entre ellas, pero en vez de basar nuestros cálculos en las puntuaciones originales otorgadas por los presos a la calidad de vida en su prisión, utilizamos ahora las puntuaciones predichas por factores distintos a los considerados antes para explicar esa calidad de vida en nuestro modelo explicativo completo (Modelo 10) ${ }^{16}$. Si las diferencias en las medias entre quienes han experimentado problemas conductuales y quienes no lo han hecho desaparecieran cuando solo consideramos estos factores ajenos a la prisión, entonces las diferencias observadas antes se deberían enteramente a los valores que los presos presentaban en las variables socio-penales, organizativas y relacionales consideradas en nuestro modelo explicativo, y a los efectos que estimábamos que tenían sobre la calidad de vida en prisión. En otras palabras, la peor calidad de vida mostrada por los presos con problemas conductuales estaría asociada enteramente a los factores socio-penales, organizativos y relacionales considerados antes. Efectivamente, las diferencias desaparecen casi completamente y dejan de ser significativas, confirmando la hipótesis de que los factores que explican una baja calidad de vida en prisión predicen igualmente bien problemas conductuales importantes en la prisión.

No obstante, falta por descartar que estos resultados no sean una consecuencia de efectos de selección no considerados anteriormente, como los que se derivarían de si las personas que muestran problemas conductuales y una baja calidad de vida en prisión lo hicieran por haber tenido problemas similares con anterioridad a su entrada en prisión. Por ello, en las tres últimas columnas de la Tabla VII hemos repetido nuestros análisis corrigiendo las puntuaciones medias por esta posible vulnerabilidad hacia las auto-lesiones importada de afuera. ${ }^{17}$ Como puede comprobarse, las diferencias en la calidad de vida media, entre los que presentan problemas conductuales y los que no, aumentan ligeramente, indicando que una parte del poder explicativo que el modelo 10 tenía para explicar la calidad de vida y los problemas conductuales en la prisión se debían en realidad a problemas conductuales anteriores. Sin embargo, el aumento en las diferencias es modesto por lo que continúan siendo no significativas.

En definitiva, podemos concluir que la calidad de vida en prisión tiene importantes repercusiones en el comportamiento de los presos en prisión.

Tabla VII.

Calidad de vida y problemas conductuales de los presos.

\begin{tabular}{|c|c|c|c|c|c|c|c|c|c|}
\hline \multirow[b]{2}{*}{ Problemas conductuales } & \multicolumn{3}{|c|}{$\begin{array}{l}\text { (1) Media 'Nota global a } \\
\text { la prisión de } 0 \text { a 10' }\end{array}$} & \multicolumn{3}{|c|}{$\begin{array}{l}\text { (2) Medias predichas } \\
\text { por factores ajenos a la } \\
\text { prisión }\end{array}$} & \multicolumn{3}{|c|}{$\begin{array}{c}\text { (3) Medias predichas por } \\
\text { factores ajenos a la prisión } \\
\text { no relacionados con auto- } \\
\text { lesiones previas }\end{array}$} \\
\hline & Sí & No & Diferencia & Sí & No & Diferencia & Sí & No & Diferencia \\
\hline Se ha autolesionado en prisión & 3,95 & 5,11 & $-1,16^{* *}$ & 0,02 & 0,00 & 0,02 & $-0,10$ & 0,02 & $-0,11$ \\
\hline Intento de suicidio en prisión & 3,86 & 5,05 & $-1,19^{*}$ & 0,01 & 0,00 & 0,01 & $-0,18$ & 0,02 & $-0,20$ \\
\hline Aislamiento en Departamento Especial & 3,99 & 5,57 & $-1,58^{* * *}$ & $-0,06$ & 0,04 & $-0,11$ & $-0,09$ & 0,06 & $-0,15$ \\
\hline
\end{tabular}

Nota: T-test para la comparación de medias de dos grupos independientes. Intervalo de confianza 95\%. 


\section{CONCLUSIÓN}

En este trabajo hemos medido la percepción de los internos de la calidad de vida en cuatro centros penitenciarios de la provincia de Barcelona. Nos interesaba especialmente contestar a las siguientes preguntas: a) ¿existen o no diferencias entre prisiones en lo que respecta a la calidad de vida?, b) ¿a qué factores son debidas dichas diferencias?; c) ¿cuáles de ellos son más relevantes para explicarlas; y d) ¿qué consecuencias comportan? Para contestar a estas preguntas hemos usado una adaptación al contexto español del cuestionario MQPL diseñado por el Instituto de Criminología de Cambridge para evaluar las prisiones inglesas y hemos realizado casi 500 encuestas entre 2013 y 2016 a las personas presas en estos 4 centros penitenciarios.

De los resultados de nuestra investigación se desprende que la calidad de vida difiere significativamente entre los centros penitenciarios analizados, obteniendo el CP1 una nota claramente superior a la media y el CP2 una valoración claramente inferior a esta. Nuestra primera conclusión es que, por lo tanto, aunque es cierto que 'una prisión es una prisión' por buenas o adecuadas que sean sus condiciones interiores y el trato que impere en ella, también lo es que algunas aserciones dichas por los presos, tales como 'esta prisión es la peor' o 'aquí se está mejor' son igualmente válidas.

Lógicamente el gran reto es intentar responder de qué dependen estas diferencias. De nuestra investigación se desprende una segunda conclusión relevante para cumplir este reto: la calidad de vida en las prisiones no se explica exclusivamente por las características personales de los presos (características sociodemográficas, antecedentes de salud mental e historial penal), sino también por cómo se organiza la prisión (la regulación del espacio y el tiempo dentro de sus muros) y por el sistema de relaciones interpersonales (entre presos y entre estos y los funcionarios y el mundo exterior) que allí se generan.

En tercer lugar, hemos intentado dirimir cuáles de entre esas dimensiones, y qué elementos dentro de ellas, son los que más contribuyen a explicar la calidad de vida en prisión. Hemos constatado que una buena organización, especialmente, una buena planificación de actividades y la ayuda recibida para planificar la puesta en libertad futura (más que los programas de tratamiento), son los factores más importantes para mejorar la calidad de vida. Además, como muestran las investigaciones inglesas (Liebling 2004), para que una prisión sea considerada mejor también es importante que los presos perciban unas buenas relaciones con el personal. A la postre, las características personales que los internos traen consigo al entrar en la prisión son las que menos logran explicar, por sí solas, la calidad de vida dentro de sus muros.
En último lugar, una vez constatada la existencia de diferencias en las percepciones de la calidad de vida de los presos hemos mostrado que estas tienen implicaciones sobre otros aspectos importantes de su vida en la prisión, en concreto, sobre comportamientos agresivos dirigidos contra sí mismos o contra otros. Hemos mostrado que estas consecuencias no se explican exclusivamente por la presencia de comportamientos similares previos a la entrada en prisión.

Nuestros resultados son descriptivamente muy ricos y únicos en la investigación sobre prisiones en España. Sin embargo, también presentan limitaciones. En primer lugar, con nuestro diseño transversal es difícil establecer una relación causal definitiva entre las variables independientes y la calidad de vida que nos permita adjudicar a unas $u$ otras el poder predictivo que ahora comparten entre ellas. Para lograrlo, necesitaríamos contar con otro tipo de datos y aplicar una estrategia distinta a la utilizada en este trabajo.

En segundo lugar, sería interesante investigar el rol que tiene la clasificación de los internos en módulos más o menos especializados para explicar la calidad de vida en prisión. En este trabajo hemos considerado a la prisión como un medioambiente homogéneo, pero hay buenas razones para pensar que las experiencias de los presos dependen en gran parte del módulo en que cumplen su condena y que la clasificación en módulos es una herramienta organizativa clave en manos de la dirección de una prisión para mejorar la calidad de vida de sus presos.

Todos estos aspectos son objeto de investigaciones ahora en curso por parte del Grupo de Investigación en Criminología y Sistema Penal de la Universitat Pompeu Fabra, de los que se dará cumplida cuenta una vez hayan finalizado. Mientras tanto, este trabajo espera haber contribuido a proporcionar una primera y rica visión de la heterogeneidad de las vivencias experimentadas por los presos en varias cárceles catalanas. Aun con todos los problemas que presenta una encuesta para medir la 'calidad de vida' en un espacio caracterizado precisamente por la falta de ella, entendemos que su aplicación ha permitido tener en cuenta no solo la duración de la condena (length) sino también de la severidad o 'la dureza' (depth) de las condiciones en las que se cumple (Downes 1988).

\section{AgRADECIMIENTOS}

Agradecemos a la Direcció General de Serveis Penitenciaris de la Generalitat de Catalunya habernos facilitado el acceso a los centros penitenciarios objeto de la presente investigación y al personal que trabaja en cada uno de ellos habernos ayudado en todo momento.

\section{Financiación}

Esta investigación se inscribe en el proyecto "Ejecución y supervisión de la pena: Calidad de la intervención, legitimidad y reincidencia”. Financiado por MINECO (Ref. DER2015-64403-P) y FEDER, UE. 


\section{NOTAS}

1. Sería quizás más neutro usar el concepto de "clima social' de la prisión en vez del de "calidad de vida". Nuestra opción por este último se debe a que así se llama el cuestionario utilizado. Véase una explicación de los cuestionarios usados en distintas evaluaciones en Tonkin y Howells (2011). Respecto a España, véase Martí (2017)

2. Uno de los centros penitenciarios en los que pasamos el cuestionario tenía dos módulos de mujeres y 20 internas fueron entrevistadas. Precisamente por considerar que las condiciones de vida de estas mujeres podían no ser representativas del centro penitenciario en su conjunto (y porque no podían ser comparadas con mujeres de los otros centros donde solo había hombres) sus encuestas fueron descartadas en nuestros análisis.

3. Inicialmente se intentó administrar el cuestionario completo, pero esto consumía más de una hora y media por entrevista. La falta de recursos humanos nos llevó a optar por administrar una versión reducida del cuestionario que pudiera ser completada en 30 o 40 minutos por un número mayor de internos y así lograr una muestra representativa en todos los centros.

4. Los resultados de los análisis son robustos y no cambian sensiblemente al utilizar criterios alternativos para dicotomizar las variables.

5. Se optó por esta traducción del término inglés 'staff por recomendación de nuestros asesores ingleses, con el argumento de que ello permitía captar la generalidad de las relaciones. En nuestra experiencia acaba siendo importante diferenciar dos grupos: el personal de vigilancia (los funcionarios de interior o 'guardias') y el personal de tratamiento (trabajadores sociales, educadores, psicólogos, juristas).

6. En el trabajo de campo han participado los siguientes investigadores e investigadoras: Elena Larrauri (CP1, CP2, CP3 y CP4), Albert Sales (CP1), Marta Martí (CP2), Cristina Güerri (CP3 y CP4), Martí Rovira (CP4), Clara Atienza (CP2 y CP3), María Estévez (CP2 y CP3), Yaiza Gómez (CP2 y CP3) y Natalia Neira (CP4).

7. Concretamente, hemos descartado las encuestas realizadas en el DMS y el MSOB de uno de los centros penitenciarios y las correspondientes al MRO en otro. Las 20 encuestas realizadas a mujeres tampoco fueron incluidas por razones ya explicadas con anterioridad (ver nota 2).

8. Tratamos esta variable como una escala para simplificar los análisis, aunque está claro que la variable es en esencia ordinal. Los resultados que mostramos más abajo son lo suficientemente robustos y coherentes como para hacernos pensar que no cambiarían utilizando otras técnicas más adecuadas al carácter ordinal de la variable.

9. Para facilitar la visualización de las diferencias en los perfiles de los internos de cada prisión, en sus aspectos organizativos y en la calidad de sus relaciones in- terpersonales, se presentan en el Anexo 1 los gráficos A1, A2 y A3.

10. La elección del CP1 como prisión de referencia tiene como consecuencia que solo en el CP2 sea la calidad de vida significativamente peor. Si cambiáramos la prisión de referencia por el CP2, veríamos que CP3 y CP4 tienen una calidad de vida significativamente superior a dicha prisión. Las diferencias entre el CP1, el CP3 y el CP4 no son significativas.

11. Estos resultados siguen resultando ciertos al aplicar la corrección de Bonferroni al nivel de significación, dividiéndolo por el número de comparaciones entre prisiones.

12. Utilizamos el $R^{2}$ ajustado, en vez del $R^{2}$ simple, para comparar mejor la varianza explicada por la prisión antes (Tabla III) y después de controlar por las variables consideradas (Tablas IV a VI), dado que el $\mathrm{R}^{2}$ ajustado resuelve el problema de que el porcentaje de varianza explicada no puede sino aumentar al introducir más variables en un modelo.

13. Hay que tener en cuenta que trabajar en talleres o destinos, además de ocupar el tiempo, reporta otro tipo de beneficios como tener una fuente de ingresos o la posibilidad de dormir solo en la celda.

14. No obstante, como puede observarse, el efecto de la variable prisión en la percepción de calidad de vida de los internos sigue siendo significativo. Esto es debido a que en nuestro modelo final siguen existiendo diferencias no explicadas (y significativas) entre el CP2, por una parte, y el CP3 y CP4 por la otra.

15. El efecto neto de cada bloque ha sido obtenido calculando la diferencia entre la varianza explicada por el modelo completo (Modelo 10) y cada uno de los modelos que pueden generarse excluyendo el bloque de variables cuya aportación se desea estimar y corrigiendo el resultado para el número de variables incluido en cada bloque ( $R^{2}$ Ajustado).

16. No sabemos exactamente cuáles son estos factores, solo que nada tienen que ver con los considerados en el Modelo 10, pues las medias para los grupos que presentan o no problemas conductuales están calculadas con los residuos (diferencias entre valores predichos y observados) del Modelo 10, donde habíamos regresado la calidad de vida sobre todas las variables socio-penales, organizativas y relacionales.

17. Las medias mostradas en las últimas columnas han sido calculadas con los residuos o diferencias entre la calidad de vida predicha por el modelo explicativo completo de regresión número 10 y la observada originariamente, una vez descontada aquella parte de la valoración de la calidad de vida que puede explicarse por la existencia de problemas conductuales previos a la entrada en prisión (lo que hemos hecho regresando primero la calidad de vida predicha en el Modelo 10 sobre las variables indicativas de la presencia de problemas conductuales previos y salvando después los residuos generados en la ecuación). 


\section{REFERENCIAS BIBLIOGRÁFICAS}

Almeda, E. 2017. "Criminologías feministas, investigación y cárceles de mujeres en España". Papers Revista de Sociología 102(2):151-181. https://doi.org/10.5565/rev/papers.2334

Becerra, J. 2012. "Las prisiones españolas vistas desde Europa. Un análisis comparado". Revista de derecho penal y criminología (3a época) 7: 381-406.

Bennett, J. 2007. "Measuring order and control in the Prison Service". Pp. 518-543 en Handbook on Prisons ( $1^{\text {a }}$ ed.), editado por Y. Jewkes, B. Crewe y J. Bennett. Cullompton: Willan Publishing.

Beyens, K. y M. Boone. 2015. "Mixing detention cultures: the Belgian-Dutch case". Pp. 479-498 en The Palgrave Handbook of Prison Ethnography ( $1^{\mathrm{a}}$ ed.), editado por D. Drake, R. Earle y J. Sloan. Basingstoke: Palgrave Macmillan. https://doi.org/10.1057/9781137403889_26

Bosworth, M. 1999. Engendering resistance: Agency and power in women's prisons. New Hampshire: Dartmouth Publishing Company.

Brandariz, J. A. 2015. "La evolución del sistema penitenciario español, 1995-2014: Transformaciones de la penalidad y modificación práctica de la realidad penitenciaria". Crítica Penal y Poder 9: 1-31.

Cid, J. 2008. "El incremento de la población reclusa en España entre 1996-2006: Diagnóstico y remedios". Revista Española de Investigación Criminológica: REIC 6: 1-31.

Clemmer, D. 1940. The Prison Community. New York: Holt, Rhineheart and Winston.

Crewe, B. 2007. "The sociology of imprisonment". Pp. 123-151 en Handbook on Prisons ( $1^{\text {a }}$ ed.), editado por Y. Jewkes, B. Crewe y J. Bennett. Cullompton: Willan Publishing.

Dâmboeanu C. y P. Nieuwbeerta. 2016. "Importation and deprivation correlates of misconduct among Romanian inmates". European Journal of Criminology 13(3): 332351. https://doi.org/10.1177/1477370815617191

Díez-Ripollés, J. L. 2006. "La evolución del sistema de penas en España: 1975-2003". Revista electrónica de ciencia penal y criminología 8: 1-25.

Dilulio, J. J. 1987. Governing prisons. London: Free Press.

Downes, D. 1988. Contrasts in Tolerance: Post-War Penal Policy in the Netherlands and England and Wales. Oxford: Clarendon Press.

Dünkel, F. 2017. "European penology: The rise and fall of prison population rates in Europe in times of migrant crises and terrorism". European Journal of Criminology 14(6): 629-653. https://doi.org/10.1177/1477370817733961

Forero, A. y D. Jiménez. 2014. "La cárcel española en (la) crisis. Mano dura y escasez: ¿hacia la esquizofrenia punitiva?". Revista de Derecho Penal y Criminología 5: 27-52.

Franke, D., D. Bierie y D. L. Mackenzie. 2010. "Legitimacy in corrections". Criminology \& Public Policy 9(1): 89-117. https://doi.org/10.1111/j.1745-9133.2010.00613.x

Gallego, M., P. Cabrera, J. Ríos y J. L. Segovia. 2010. Andar 1 km en línea recta. Madrid: Universidad Pontificia de Comillas.

Gallizo, M. 2013. Penas y personas: 2810 días en las prisiones españolas. Madrid: Debate.

González, I. 2012. "La cárcel en España: mediciones y condiciones del encarcelamiento en el siglo XXI". Revista de derecho penal y criminología 8: 351-402.

Irwin, J. y D. R. Cressey. 1962. "Thieves, convicts and the inmate culture". Social problems 10(2): 142-155. https:// doi.org/10.2307/799047

Jacobs, J. 1977. Stateville: The penitentiary in mass society. Chicago: University of Chicago Press.

King, R. D. y K. McDermott. 1995. The state of our prisons. Oxford: Clarendon Press.
Kruttschnitt, C. y A. Dirkzwager. 2011. "Are there still contrasts in tolerance? Imprisonment in the Netherlands and England 20 years later". Punishment \& Society 13(3): 283306. https://doi.org/10.1177/1462474511404333

Kruttschnitt, C. y R. Gartner. 2003. "Women's imprisonment". Crime and Justice 30: 1-81. https://doi.org/10.1086/652228

Liebling, A. 2004. Prisons and Their Moral Performance: A Study of Values, Quality, and Prison Life. Oxford: Oxford University Press.

Liebling, A. y S. Maruna. 2005. The effects of imprisonment. New York: Routledge.

Liebling, A. 2006. "The role of the prison environment in prison suicide and prisoner distress". Pp. 16-28 en Preventing suicide and other self-harm in prison, editado por G. E. Dear. Basingstoke: Palgrave-Macmillan.

Liebling, A., S. Hulley y B. Crewe. 2011. "Conceptualising and measuring the quality of prison life". Pp. 358-372 en The SAGE Handbook of Criminological Research Methods, editado por D. Gadd, S. Karstedt y S. F. Messner. London: Sage. https://doi.org/10.4135/9781446268285.n24

Liebling, A. y B. Crewe. 2012. "Prison life, penal power and prison effects". Pp. 895-927 en The Oxford Handbook of Criminology ( $5^{\mathrm{a}}$ ed.), editado por M. Maguire, R. Morgan y R. Reiner. Oxford: Oxford University Press. https://doi. org/10.1093/he/9780199590278.003.0030

Logan, C. H. 1992. "Well kept: Comparing quality of confinement in private and public prisons". Journal of Criminal Law and Criminology 83(3): 577-613. https://doi. org/10.2307/1143839

Martí, M. 2017. "El estudio de la calidad de vida en prisión. Una revisión bibliográfica de la investigación en España y principales planteamientos internacionales". InDret: Revista para el análisis del Derecho 3: 1-34.

Moos, R. H. 1968. "The assessment of the social climates of correctional institutions". Journal of research in crime and delinquency 5(2): 174-188. https://doi. org $/ 10.1177 / 002242786800500207$

Pratt, J. y A. Eriksson. 2012. "In defence of Scandinavian exceptionalism". Pp. 235-260 en Penal Exceptionalism? Nordic Prison Policy and Practice, editado por T. Ugelvik y J. Dullum. New York: Routledge.

Prison Reform Trust. 1992. The Woolf Report: A summary of the main findings and recommendations of the inquiry into prison disturbances. London: Prison Reform Trust. Disponible online en: http://www.prisonreformtrust.org.uk/Portals/0/ Documents/Woolf\%20report.pdf [Consulta el 03/05/2016].

Rafter, N. H. 1985. "Gender, prisons, and prison history". Social Science History 9(3): 233-247. https://doi.org/10.1017/ S0145553200015078

Ríos, J. C. y P. Cabrera. 1998. Mil voces presas. Madrid: Universidad Pontificia de Comillas.

Sparks, J. R. y A. E. Bottoms. 1995. "Legitimacy and order in prisons". British Journal of Sociology 46(1): 45-62. https://doi.org/10.2307/591622

Sykes, G. M. [1958] 2007. The Society of Captives. Princeton: Princeton University Press.

Tonkin, M. y K. Howells. 2011. "Evaluation of regimes and environments". Pp. 249-270 en Research in Practice for Forensic Professionals, editado por K. Sheldon. New York: Routledge.

Tyler, T. R. 1999. "Why people cooperate with organizations: An identity-based perspective". Research in organizational behavior 21: 201-246.

Tyler, T. R. 2010. "Legitimacy in corrections: Policy implications". Criminology \& public policy 9(1): 127-134. https:// doi.org/10.1111/j.1745-9133.2010.00615.x 


\section{ANEXO 1: DIFERENCIAS ENTRE PRISIONES}

Los gráficos presentados en este anexo expresan la proporción de internos en cada prisión con respuestas positivas en las variables independientes binarias, o sus medias en las variables de intervalo, todas ellas expresadas relativamente, es decir, en unidades de desviación típica respecto a la proporción o media general observada para todas las prisiones. Estos gráficos nos sirven también a modo de descripción de la distribución de las variables independientes en cada prisión. Nos fijamos primordialmente en las desviaciones superiores a dos, para obtener el perfil más marcado de los internos de cada centro.

Gráfico A1.

Historial del interno.

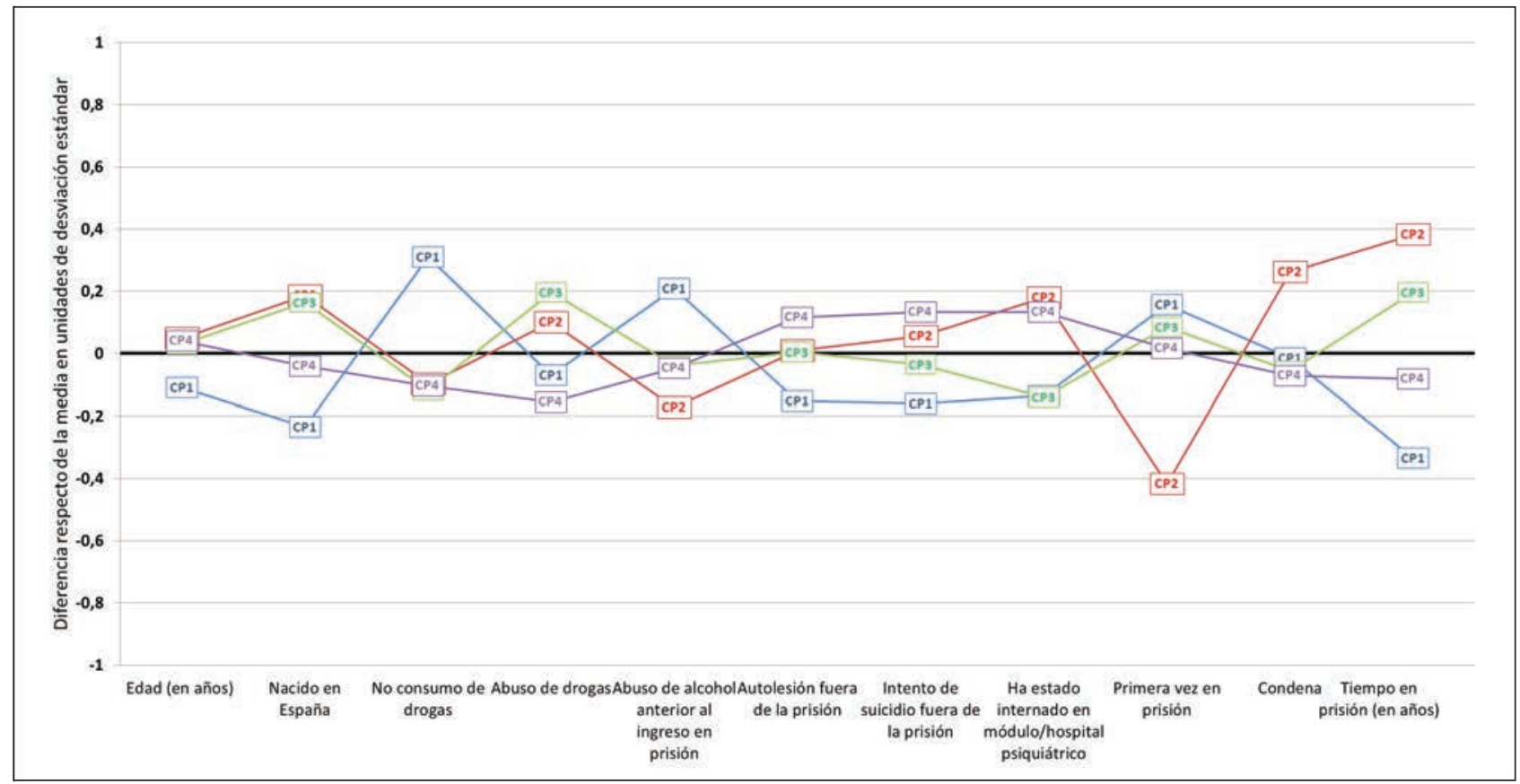

Gráfico A2.

Organización de la prisión.

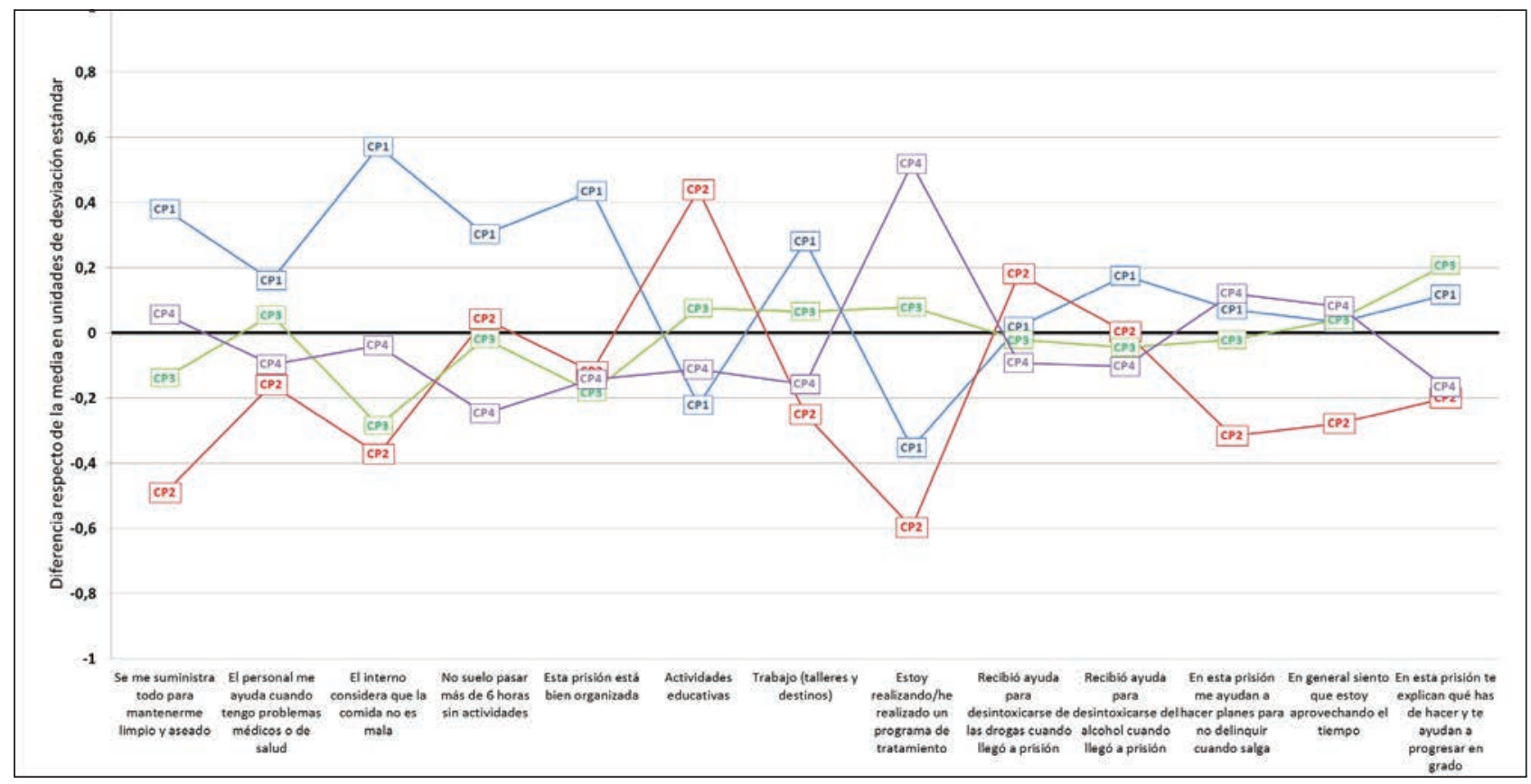


Gráfico A3.

Relaciones interpersonales.

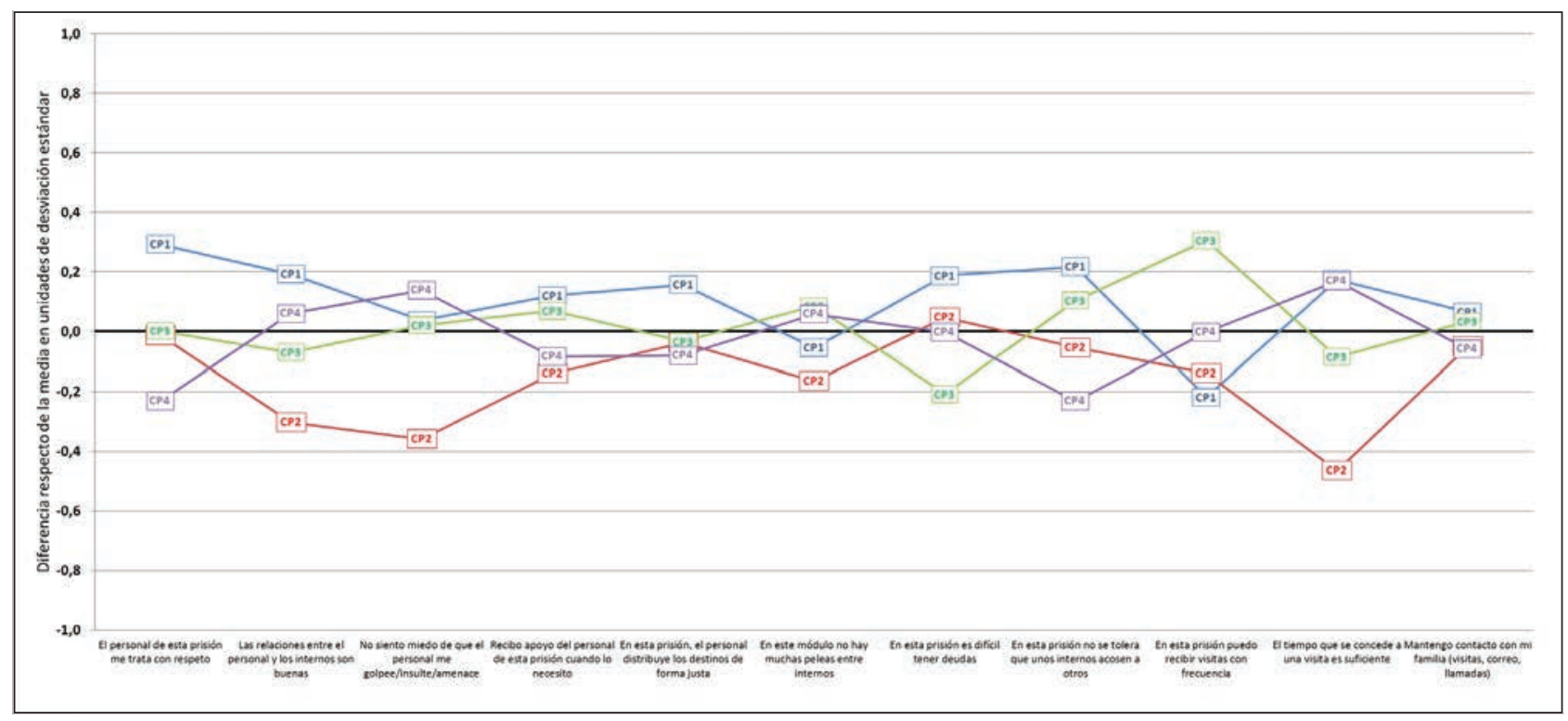

JORGE RODRÍGUEZ es doctor en Sociología por la Universidad Norteamericana de Nortwestern. Actualmente es profesor agregado Serra Hùnter en la Universidad Pompeu Fabra donde también ejerce como Coordinador del Programa de Doctorado del Departamento de Ciencias Políticas y Sociales. Su investigación ha estado distribuida en tres grandes líneas de investigación: la sociología política, la estratificación social el estudio de las desigualdades sociales y, por último, la criminología y la atención a los colectivos marginados.

ELENA LARRAURI es Catedrática en Derecho Penal y Criminología en la Universitat Pompeu Fabra. Sus líneas de investigación son el sistema penitenciario, los antecedentes penales, el sistema de penas y el análisis de género en el sistema de justicia penal. Ha sido galardonada con las Becas Fulbright-la Caixa y Alexander von Humboldt. Fue Presidenta de la European Society of Criminology (2007-2010) y profesora visitante "Visiting Fellow" en el All Souls College (University of Oxford) durante el curso 2013-14. Es fundadora del Grupo de Investigación en Criminología y Sistema Penal.

CRISTINA GÜERRI FERRÁNDEZ es graduada en Criminología y Políticas Públicas de Prevención (Universidad Pompeu Fabra) y ha cursado el Máster interuniversitario en Criminología y Ejecución Penal (UPF, UAB, UdG y UOC). En ese período obtuvo una Beca de Colaboración (AGAUR) para la realización de tareas de investigación y participó en el Programa Erasmus en la Universidad de Utrecht. En la actualidad, ha obtenido una beca para la Formación del Personal Universitario (Ministerio de Educación) para la realización de una tesis doctoral sobre el personal de interior de los centros penitenciarios. 